Florida International University FIU Digital Commons

$7-15-2010$

\title{
Mock-ups in design : the implications of utlizing [sic] a mock-up review process in professional practice
}

Charles M. Boggs

Florida International University

DOI: $10.25148 /$ etd.FI14051179

Follow this and additional works at: https://digitalcommons.fiu.edu/etd

Part of the Art and Design Commons

\section{Recommended Citation}

Boggs, Charles M., "Mock-ups in design : the implications of utlizing [sic] a mock-up review process in professional practice" (2010). FIU Electronic Theses and Dissertations. 1709.

https://digitalcommons.fiu.edu/etd/1709 
FLORIDA INTERNATIONAL UNIVERSITY

Miami, Florida

MOCK-UPS IN DESIGN: THE IMPLICATIONS OF UTLIZING A MOCK-UP

REVIEW PROCESS IN PROFESSIONAL PRACTICE

A thesis submitted in partial fulfillment of the

requirements for the degree of

MASTER OF ARTS

in

INTERIOR DESIGN

by

Charles M. Boggs

2010 
To: Acting Dean Brian Schriner

College of Architecture and the Arts

This thesis, written by Charles M. Boggs, and entitled Mock-ups in Design: The Implications of Utilizing a Mock-up Review Process in Professional Practice, having been approved in respect to style and intellectual content, is referred to you for judgment.

We have read this thesis and recommend that it be approved.

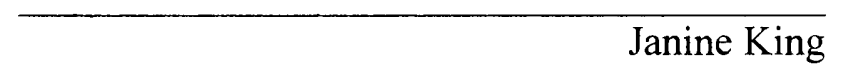

Sarah Sherman

Phillip Abbott, Major Professor

Date of Defense: July 15, 2010

The thesis of Charles M. Boggs is approved.

Acting Dean Brian Schriner

College of Architecture and the Arts

Interim Dean Kevin O'Shea

University Graduate School

Florida International University, 2010 


\section{DEDICATION}

I dedicate this thesis to my parents, Richard and Katherine Boggs. Their

unwavering belief in me inspires everything I do. Without their love and support, the completion of this thesis would not be possible. 


\section{ACKNOWLEDGMENTS}

I wish to thank the members of my committee for their time, patience, and dedication. Above all I wish to thank them for providing me the opportunity to pursue something I love in a supportive environment that both challenged me and motivated me to do my best. The drive to live up to and exceed their high expectations has propelled me forward and inspired me to do work that makes a difference, as they have made all the difference for me.

I must also acknowledge the contributions of Mr. Chip Young and Mr. Greg Walton. These talented professionals gave me my first exposure to the art of teaching design. By allowing me to come into their classrooms and assist them with their students, they inspired a passion and new direction for my life and career. 


\title{
ABSTRACT OF THE THESIS \\ MOCK-UPS IN DESIGN: THE IMPLICATIONS OF UTILIZING A MOCK-UP REVIEW PROCESS IN PROFESSIONAL PRACTICE
}

by

\author{
Charles M. Boggs
}

Florida International University, 2010

Miami, Florida

Professor Philip Abbott, Major Professor

The purpose of this research is to examine the use of a mock-up review process in interior design projects to better understand the implications of using such a process within the standard professional practice model. The research consisted of interviewing design professionals who utilize mock-ups as part of their standard of practice. These interviews were centered around two groups - those working in shipbuilding, where mock-ups have a long history, and those working in land-based projects, where mock-up use is rare. Analysis of the interviews indicated a positive relationship between mock-up use and collaboration, innovation, and problem solving. The interviews also brought to light concerns on behalf of all the professionals surveyed about the current practice model in land-based building design and construction projects within the United States. The positive relationships shown in the thesis support further research to explore how mock-ups can be best utilized in interior design. 
I. INTRODUCTION

Statement of the Problem 1

Objectives 2

Background 2

Integrated Practice and Knowledge Creation 5

$\begin{array}{ll}\text { Challenges in Collaboration } & 7\end{array}$

$\begin{array}{ll}\text { Opposing Views } & 10\end{array}$

Mock-ups in Design 11

Precedent: Cruise Ship Design 13

$\begin{array}{ll}\text { Mock-ups in Land-based Practice } & 19\end{array}$

II. METHODS 25

Qualitative Approach $\quad 25$

Data Collection $\quad 28$

Data Analysis $\quad 30$

III. RESULTS 33

The Coding Frame: Identifying the Major Themes 33

The Interviews $\quad 38$

Interview 1: Shipbuilding - Owner / Client 39

Interview 2: Shipbuilding - Design Senior Leadership 45

Interview 3: Land-based - Design Senior Leadership $\quad 50$

Interview 4: Land-based - Design Management $\quad 54$

Coming Together: Exploring the Interviews Collectively 60

$\begin{array}{ll}\text { IV. CONCLUSION } & 68\end{array}$

Discussion $\quad 68$

Limitations $\quad 69$

Lessons from the Research $\quad 71$

Recommendations: Areas of Future Research 72

$\begin{array}{ll}\text { LIST OF REFERENCES } & 75\end{array}$

$\begin{array}{ll}\text { APPENDICES } & 77\end{array}$ 
FIGURE

PAGE

1. Coding Frame 33

$\begin{array}{ll}\text { 2. Code Chart } & 37\end{array}$

3. Interview 1: Identified Themes 40

4. Interview 1: Thematic Clusters 40

5. Interview 2: Identified Themes 46

6. Interview 2: Thematic Clusters 46

7. Interview 3: Identified Themes 51

8. Interview 3: Thematic Clusters 51

9. Interview 4: Identified Themes 55

10. Interview 4: Thematic Clusters 56

11. Collective Identified Themes 60

12. Collective Thematic Clusters 61 


\section{INTRODUCTION}

\section{Statement of the Problem}

Interior Design professionals are being faced with a convergence of important issues that will impact their practice in the years ahead. These issues affect how Interior Designers are trained, practice, and collaborate with other stakeholders in projects. As Interior Design was only recently established as an independent profession, it has a severely limited Body of Knowledge. (Martin \& Guerin, 2006) This lack of a professional knowledge foundation makes adapting to changes more difficult, as designers don't have a rich history of recorded experience from which to draw. Today, professionals are seeing their primary practice model shift from one of a Master-Builder approach with separated roles and responsibilities to a model of Integrated Practice wherein complex teams consisting of Owner, Architect, Interior Designer, Engineers, Contractor, and various consultants work together in large teams that require intense collaboration and where roles often overlap. (Pressman, 2007 and Harman-Vaughan, 2008) As they adapt to this new model they rely on methods of knowledge creation to foster competitive advantage. (Lee \& Kim, 2001) In such a time, the profession will need to examine techniques of practice to look for ways of improving and refining their methods. Already in use in many creative professional settings, and being explored in limited use in design, is the utilization of a mock-up review process. The study proposes to examine the mockup process where it has been incorporated into a firm's standard practice model to ascertain the benefits or negative consequences of doing so. By extension, this study 
aims to expand the Interior Design Body of Knowledge in the realm of Professional Practice.

\section{Objectives}

The primary goals of the research include ascertaining the benefits and negative consequences of incorporating a mock-up review process in the practice model for Interior Design, evaluating its impact on collaboration, and exploring the potential for wide scale adoption within the profession. Specific objectives include identifying and evaluating the motivating factors behind a subject firm's adoption of the mock-up review process, analyzing the way in which the process was actually utilized, evaluating whether the firm's intended goals were realized, and discovering what unintended consequences revealed themselves.

\section{Background}

The process model for designing and constructing buildings and their interior environments is in a period of dramatic change. The primary model for most of the $20^{\text {th }}$ Century followed a linear methodology in a design-bid-build process. In this model, a project team compromised of players with distinct roles - Client, Designer, and Contractor - complete step by step project tasks that lead them through first designing a project, then sending the project out to bid among a group of competing contractors, and finally through constructing the project. While this model is still found in practice today, 
a more complex team model is replacing it where the traditional roles and step-by-step process no longer exist. (Harmon-Vaughan, 2008) This change is being driven by marketplace demands for buildings that are faster to design and build, are of lower cost, are sustainable, have more thoroughly resolved designs, and are of higher construction quality than buildings of the past. (Pressman, 2007)

As Harmon-Vaughan (2008) explains, this growing complexity is driven by changing technology, new construction methods and delivery systems, and dramatic changes in project financing. The project financing in particular has changed the way in which the concept of 'Client' is defined. Clients can now be thought of as the financing entity, occupants, or facility managers - where they had previously been understood as the building owner in most cases. Sometimes a project will have a different 'client' for each of these functions. Design teams must now contend with these multi-faceted, or even multiple, clients working together on the same project. These clients often have very different ideas of success from the end-user, which can create challenges for the designers. With so many different priorities, project teams will often have to shift and redirect their goals to address these different and changing needs.

The relationship between design teams and contractors are also changing in terms of how they are organized and how they function. The 'Master-Builder' architect or engineer has been replaced by a complicated team of multi-disciplinary players with various expert consultants for specific areas of a project. (Harmon-Vaughan, 2008) These participants include architects, interior designers, engineers, lighting designers, technical systems 
designers, acoustic specialists, et al. Contractors are now a set of subcontracted companies assembled into a construction team with sub-contractors for each specialized discipline. With so many players now involved, these broad, collaborative teams must create a shared vision with agreed upon goals to achieve the desired results from the final product. (Harmon-Vaughan, 2008) The teams must also work to create an environment of trust and respect in order to help manage the complexity of issues that arise. (HarmonVaughan, 2008)

In Lee \& Kim's (2001) research, they illustrate that at the heart of professional practice is the creation of knowledge to foster greater competitive advantage. They identify a resource-based view of firms that suggests that organizational resources and capabilities are the principle sources of competitiveness and sustainability within a profession. Based on this view, they point out that organizational knowledge such as operational routines, skills, and 'know-how' are the most valuable corporate resources and the ability of a firm to capitalize on these elements is the most critical competitive advantage available, especially in a highly dynamic and changing professional environment. Therefore, an investigation on the techniques available to Interior Design to foster knowledge creation goes hand-in-hand with identifying methods by which firms can foster a competitive advantage within the profession. 


\section{Integrated Practice and Knowledge Creation}

Pressman (2007) defines this new model of design and construction as Integrated

Practice. In this model, design and construction no longer fit into two distinct phases, but overlap one another in a back and forth relationship, where the contractor is not merely the winning bidder, but an active participant in the design-build process from the early stages. The contractor is brought onboard earlier in order to help map out the construction process as construction begins before a design is completely approved. The consequences for design firms of this new model affect firm culture, standard contracts (and contract documents), compensation, education, liability concerns and insurance, and risk management. In short, every individual aspect is being redefined along with the overall process itself.

Another important aspect of the design and construction process is its use by firms as a tool for Knowledge Creation. As Robertson, Scarbrough, and Swan (2003) explain, professional service firms' main business is the "provision of specialized consultancy." Design firms are just one of many types of professional service firms. All such firms provide an important arena for examining how the institutions themselves influence knowledge creation as "their survival depends on their ability to mobilize and synthesize professional bodies of knowledge." In other words, professional service firms rely heavily on the body of knowledge actively created by the firm during the act of performing their job within their profession. They build on past experiences to help them adapt to changing conditions and to confront new and unexpected problems. As 
Integrated Practice represents a new process model, firms will have to utilize their ability to generate knowledge in order to address the unique concerns of this new method of practice.

Interestingly, the research done by Robertson, Scarbrough, and Swan presents three distinct ways in which different kinds of firms engage in knowledge-creating activities. They identify scientific methods used by such professions as medicine and engineering that rely on judgments of fact established through experimental processes to generate new knowledge. On the other hand, normative professions, such as law or the clergy, rely on value judgments established through debate to create new knowledge. Thirdly, they identify professions that use a hybrid version of these processes to create new knowledge within their firms. They refer to these professions as syncretic professions. (Robertson, Scarbrough, \& Swan, 2003) Design is an example of such a syncretic profession. Within the design process, practitioners often employ both factual/science-based investigation (such as material testing, lighting measurements, and energy consumption) and valuebased investigation (social-cultural assessments of aesthetics) in order to generate new knowledge necessary to engage successful design projects. Mock-ups could potentially serve as a strategic tool for developing knowledge necessary to address the issues unique to each real life context. 


\section{Challenges in Collaboration}

As the profession moves towards using the Integrated Practice model as its standard practice process, it must overcome the issues that have always plagued collaborationintensive methods. Margerum (1999) examined collaboration for its weaknesses and looked into solutions to overcome them. He defines the creation of 'shared capital' by collaborative teams and shows how through its use teams can face and overcome problems. Shared capital consists of three types of collective experience-social capital, intellectual capital, and political capital. Social capital exists in the form of trust, norms, and networks. Intellectual capital is basically shared knowledge and it exists in the form of agreed upon facts, shared definitions, and mutual understanding. Political capital is created through alliances and agreements that can improve the possibility of implementation. (Margerum, 1999)

Margerum's research concluded that failures in collaboration often stem from weaknesses in implementation. Sources of these failures can be attributed to poor communication, problems with resolving conflicts, personality differences, extremely difficult problems, long histories of antagonism, and inadequate funding to support implementation. Failures were most common in three areas:

- Stakeholders often find difficultly in strategically mapping out project goals and objectives. Instead of producing a list of specific tasks and responsibilities, they create a wish list of desired actions that fails to provide a process structure that would ensure effective decision making in problematic 
situations. These wish lists are often vague and ill defined, leaving the team members with an unclear definition of their roles and expected results.

- Stakeholders often fail to adequately consult and interact with what Margerum terms 'the public' throughout planning and implementation. The public for design process purposes can be thought of as the final user group of any project - the group that will interact with the built environment the most. This separation from the public can lead to an insulated work environment where the final product does not meet the needs and expectations of all vested parties, including this final user group.

- Many stakeholders participate in the process from a one-sided point-of-view, offering information, but not changing their own policies, procedures, and actions to support implementation. Simply being present and answering directed questions fails to meet the criteria for being fully involved and collaborative. Every member of a project team must actively participate for the full potential of success to be realized. Fully embraced participation leads to a more thoughtful exchange of ideas, new perspectives, and a sense of shared responsibility to the outcome.

To overcome these weaknesses, Margerum suggests that implementation should be guided by a Common Information Set wherein stakeholders will come together to offer perspective and analyses to develop a better shared understanding of their project. The Common Information Set is a collective documenting of a project's scope, methods, and goals. It is what the team, as a collaborative group, agrees to abide by as their core, 
defined purpose and serves as a reference for all team members. After establishing this Common Information Set, stakeholders should guide implementation using a Cooperative Plan or Policy wherein stakeholders clearly identify and understand goals, actions, and responsibilities. Finally, stakeholders should employ Joint Decision Making to actions that are especially complex and dynamic. (Margerum, 1999) In other words, Margerum is advocating a syncretic system of knowledge creation and sharing in order to strengthen the collaborative process.

Thus far, design pedagogy has been largely viewed as having failed to adequately prepare future design professionals for the collaborative work environment. While Pressman (2009) briefly touches on this, the issue is hardly new. Over twenty years ago, Joroff and Moore examined the issue in their research on Case Method teaching and design process management. The researchers brought to light the growing need for collaboration within the profession and the lack of documented in-depth Case Methods to use as teaching tools. (Joroff \& Moore, 1984)

They point out that most architectural (and design) studio settings do not focus on collaboration and team process, but instead focus on training an individual for working alone. However, most practice does not occur following this model. The authors promote the Case Method of teaching, an experiential method that would be very useful in helping provide students specific approaches and methodologies to managing the collaborative system. The biggest obstacle in teaching via the Case Method approach is the lack of documentation and study of specific cases among the design disciplines. 
Unlike law, business, or medicine that have a long history of Case Method teaching and provide considerable resources to documenting cases, architecture and design have failed to do so. (Joroff \& Moore, 1984) Indeed, Martin and Guerin also cite this oversight in their argument for the Interior Design profession to establish a Body of Knowledge based on collected and documented cases. (Martin \& Guerin, 2006)

This failure of the educational system needs to be corrected in order to better prepare future professionals for the new realities of practice. In particular, it must give them some knowledge of how to work in teams that follow the Integrated Practice model. The need for a highly structured and agreed upon strategy for collaboration drives how projects are managed and organized. This strategy must be actively maintained and include methods for feedback, evaluation, and re-examination of procedures and tactics as projects move forward. Students should be thoroughly exposed to these issues. (Joroff and Moore, 1984) That Pressman, along with Martin and Guerin, are highlighting these same needs and concerns some 25 years after Joroff and Moore raised them is a matter of concern for the profession. Its educational system must be able to respond and adapt to the needs of the profession in a timely manner - something at which it seems to be failing.

\section{Opposing Views}

It needs to be noted that there are those within the design professions that oppose the collaborative model as the ideal practice method. Spiller's editorial in Architectural 
Design, titled "Mythic Design," is such an example, wherein a regarded member of the profession speaks out against what he sees as the degradation of creativity through the collaborative process. The author is a Professor of Architecture and Digital Theory and the Vice Dean at Bartlett University College London. He feels that collaboration, with its massive teams, results in projects that are mundane with little lasting contribution to society and culture. He explains that the new technologies for knowledge creation and management, such as Building Information Modeling (BIM), do not address how the genesis of design occurs and creates a watered-down process where designs are implemented by what can be input, not by creative vision. He insinuates that the collaborative model is corrupted by capitalism and is moving forward to service itself, not to provide a better model for architectural service. He recognizes that this is becoming the predominant process model as those within the profession are following the bandwagon and few dare to speak out against it. (Spiller, 2007)

\section{Mock-Ups in Design}

Whether one sides with Spiller against collaboration, it is logical to agree with him that the profession is embracing the model of Integrated Practice because of the competitive advantage it creates for firms. As the profession continues to pursue this course, the need to evaluate and refine it will also continue. It is also necessary to examine whether Spiller's argument - that collaboration kills creativity - can be addressed. Can Integrated Practice have an organization that actually fosters creativity rather than fight it? We suggest that the organizational capability for creativity may lay in how firms and 
individual designers create and manage knowledge in order to sustain a competitive advantage. Examining Integrated Practice from this perspective leads us to explore examples of processes already in use that may address the complex issues associated with leveraging organizational knowledge and communication into creative production. This study has identified the mock-up review process as a source of such exploration. This highly structured process is inherently collaborative and has evolved to serve many different areas of the practice, yet it remains largely unused by the general profession. In this review, the different ways in which mock-ups are used will be identified and the specific method of use as the subject of study will be identified.

While not part of standard practice in Interior Design (and, indeed, in the related profession of Architecture), mock-ups have become a part of the process standard in many other creative professions already. For example, in the special effects and computer animation industries, mock-ups in the form of animation tests have become standard practice. For example, before Disney would commit the funds to produce Pixar's Toy Story, the animators had to produce a 30 second short film that would simulate the look of the final film. In essence, they had to prove to their "client" (Disney) that the innovative method of animation they were proposing would produce a viable motion picture by creating a smaller version of the film that would enable the animation team to explore processes of production while also illustrating the quality and look of the final product. This became the reference standard for the work on the finished film. (Paik, 2007) Industrial models have long used mock-ups as part of their standard process. The automobile industry also uses mock-ups in many ways. Mock-ups 
are often engineering test mules used to test various new technologies and to determine vehicle performance. Designers often use full-scale clay models that can be finished identically to a production car in order to have the design reviewed, as well as to test the design for performance qualities like aerodynamics. These models are often shown at consumer clinics to gage public reaction to a design prior to proceeding with production. (Lockledge, Mihailidis, Sidelko, \& Chelst, 2002) Further trial and error, test and review processes can be found in everything from furniture design to graphic design. In all of these examples, the mock-up process also represents a scaled down version of the overall process needed to bring the final product into production. Every party that is responsible for creating the final product - be it a film or a car - must be engaged. Here, the mock-up process itself serves as a method of knowledge creation, serving to educate the players about the larger project process in which they collaborate. In this sense the mock-up isn't just testing a design; it is also testing collaboration and providing a vehicle of knowledge creation and management. Could mock-ups serve a similar role in Interior Design? How is the process already being used within the profession?

\section{Precedent: Cruise Ship Design}

One such area where Interior Designers and Architects are using mock-ups is in cruise ship design. This specialized area of practice uses mock-ups as a standard method within their design process and is, therefore, likely to provide insights that can be applied to the profession as a whole. On the other hand, there are some important and significant differences between the ways in which cruise ship projects and land-based projects are 
setup and organized. The differences between these process models make some issues difficult to translate from cruise to land-based projects. Therefore this review will look at the cruise ship process as whole and the use of mock-ups in particular for lessons that can be examined throughout the course of the study. It should be noted that the researcher's knowledge of the cruise ship design process comes from several years designing for and managing cruise ship projects across a number of companies and brands.

One of the most important features of the cruise ship model that makes it relevant to examine is that it has evolved over three decades of dedicated use and its inclusion of mock-ups has been part of its history since the early stages of its development. The process model for cruise ship design and construction began in 1970 With Royal Caribbean's launch of the first custom-built cruise ship, the Song of Norway followed by the Nordic Price and the Sun Viking in 1971 and 1972 respectively. Indeed, CruiseCritic.com refers to these ships as the "prototype for virtually all cruise ships since." (Newman, n.d.) Before that development, the cruise ship industry had grown by purchasing retired vessels and converting them to cruise ship use. In many ways, the design and construction of these vessels served as a large-scale mock-up process for the way in which cruise ships would come to be built. With the explosion of cruising popularity, all the major cruise lines began commissioning their own ships and the structured design and construction process evolved, based on the pioneering Royal Caribbean model. (Garin, 2005) 
Secondly, many features of the process, such as a highly structured phased schedule and multi-disciplinary collaborative team make-up, are found in land-based design and can allow the process to be considered a hybrid version of design-bid-build and the Integrated Practice design-build model. Most cruise ships are built following a model that consists of a team made up of the Owner (the cruise line), the Shipyard, a team of designers, and various groups of expert consultants and subcontractors. All participants in the collaborative team are chosen for their expertise and skills - whether it be spa design, lighting, specialized construction, or any of the myriad of other specialized areas that have developed. Many of these team members have long histories with working in the industry and relationships have been built over decades of working together. (Anon, Naval Architect, 2000)

The cruise ship process is inherently strategic with benchmarked goals and stated objectives that drive all the individual space project teams to work together as a larger team responsible for the entire ship. Concept design starts about a year ahead of steel production with the Owner, shipyard, and design teams charette-ing the entire ship. An overall General Arrangement plan (GA) of the ship and its decks is agreed upon and a construction contract is signed with the Yard. Once this takes place, design of the individual spaces by selected design firms begins in earnest. At around a year into the process, individual GA's exist for every space of the ship and steel design is locked in, so construction can begin. From this point, designs continue to change and evolve respecting the agreed upon primary steel locations. Once this occurs, the process truly does become design-build with the shipyard and design teams moving ahead at full pace, 
with construction sometimes trailing just behind finalized design. Because of this, the teams on a cruise ship project work together in a highly organized process in which collaboration meetings can be scheduled up to a year in advance. About six months prior to the interior fit-out of a space (longer for the mass-produced cabins and for elements which interact with the exterior), the selected sub-contractors begin manufacturing mockups.

Mock-ups are an important element of cruise ship design during the design and construction process. Every area in the ship is allocated mock-ups for areas of concern either in design or in construction detailing. This gives the Owner a chance to review the design and construction of feature elements prior to final construction onboard. The Owner can then approve whether a design proceeds through as presented or whether it is modified. Additionally, the shipyard is able to test construction methods to ensure quality of construction - an important step given that the shipyard holds the ultimate liability for the construction of the ship, not the designer. Indeed it is this liability that serves as a major driving force behind the inclusion of mock-ups in this process. By testing the construction and requiring Owner-approval before proceeding, both Owner and Shipyard receive assurances to proceed with construction in good faith. The chance to have this review can save the Owner the cost and time constraints of modifying a space once construction is completed.

In this regard, the mock-up process as practiced in shipbuilding follows the strategy of simulation research as described by Groat and Wang (2002). Simulation research 
involves 'carefully controlled replications of real-world contexts' for the purposes of studying the dynamic interactions that occur in the setting. For designers, these interactions occur in many ways, including how materials relate to one another, how construction detailing affects design aesthetics, and how people physically experience design elements. The key component to simulation research is that it is involved in manipulating elements for the sake of gaining knowledge that can be adapted to the real world context under study. This makes it different than model building or the production of renderings, which are used as representations of the space as opposed to simulations. Simulations are meant to be learning tools that are studied and adapted - they are not meant to represent a finished design.

Liability, as described earlier, is one of the major differences between the cruise ship process and land-based projects and one of the key reasons we are unable to make a direct comparison between the types of work. Unlike land-based projects, the shipyard serves in a similar fashion to an automobile manufacturer, giving the ship itself a warranty and a guarantee if you will. In land-based work, liability is a much more complex issue, with different parties taking on different levels of responsibility - there is no one party that is ultimately responsible for the final product. This sets up a process wherein the contractual relationships between the parties differs significantly from the land-based model and, therefore, the motivating factors behind parts of the process, such as using mock-ups, may be driven by factors not found in land-based design. Another difference lies with the construction side of the process and issues of mobilization and time. Land-based contractors may have different teams they can mobilize on other 
projects if one particular project may fall behind schedule, a shipyard has one staff and one location for all their work. If a ship fails to deliver on time, the project slotted for construction after it in the schedule is also delayed - having an impact on the yard's contracts with multiple owners.

Another way in which the cruise ship design practice is different is that it is a highly specialized area of practice with its own construction methods, codes and guidelines. When new firms are brought into the process, such as occurred during the design of Celebrity Solstice, the experienced firms mentor them in the specifics of ship construction. It is not possible for them to merely apply lessons learned from their standard land-based practice. They must be educated in the construction process and regulations. Solstice saw many design firms working together to ensure a cohesive look to the ship while still celebrating individual space designs. (Hunt, 2009) Other cruise lines have used one design firm for all of a ship's public spaces. In both scenarios, the Shipyard serves as both the engineer and primary hull contractor (another difference), helping the designers coordinate regulation and life safety issues and advising on issues of construction detailing. (Hunt, 2009) Subcontractors are chosen, based on individual skills, to assemble the public space interiors of the ship. The differences all add up to a system where the relationships are highly organized and collaborative. The close relationship between the owner, designer, and shipyard (along with the various subcontractors and consultants) helps ensure that the design direction is preserved, the Owner's desires achieved, and the construction of the vessel meets the expected levels of quality. 
In conclusion, the cruise ship design process is a highly valuable example from which we can draw lessons to apply toward land-based design. Its adoption of a mock-up process as a standard of practice illustrates how such a process can be used to the benefit of design. Unfortunately, some key differences exist - many of them in the structured relationships of the involved parties - which make it difficult to translate some of those lessons directly to the land-based model. Much of this has to do with the different motivating factors involved in those relationships. To see whether mock-ups truly have a place in land-based design we need to examine how they are already being used there.

\section{Mock-Ups in Land-based Practice}

A review of the literature about design firm use of mock-ups reveals differences in their use within the profession today. The lack of uniformity in application of mock-up use is derived from the differences in the purpose regarding the types of knowledge being sought in the process. For example, highly technical design applications will often use mock-ups to test lab environments and equipment layouts. In these cases, the creation of mock-ups is driven by the end-user and the technical requirements of the project. We use these motivating factors to categorize their use within the profession and will refer to this first classification type as User-Driven/Techmical. Within this type of mock-up use, two different procedures emerge. Some have off-site mock-ups built where overall arrangements and specific workstation setups can be examined. Others utilize in-place mock-ups built on-site within a project environment. These in-place mock-ups still allow for changes to occur, but generally not to the same extent as an off-site mock-up. As a 
trade-off they become part of the final product (thus reducing the cost of building the mock-up) and can serve as an in-place example of quality standards to be met. (Joyce, 2003)

A second way in which we find mock-ups being used will be classified as UserDriven/Function. By this we are identifying the use of mock-ups that are again being driven by the ability to perform properly for the end user. In contrast, however, these mock-ups are not testing something as technically specific as a lab environment, but are testing overall environments for their functional performance as it relates to the human interactions taking place. For example, these mock-ups would look at how different workplace setups function and their effect on the work performance of the end-users. As a result, in most cases, the end-user is also part of the client organization. We can find an example in the design of Radio Shack's new corporate headquarters. Here, architecture firm HKS designed a functioning office mock-up called Idealab at the request of the client. Idealab allowed them to test a user-group for months, eliciting comments and feedback that accompanied hours of observation to determine which workplace setups best functioned according to how the client actually used them. In this case, design changes could be incorporated long before final construction and with the added assurance of having been tested and approved in real-world working situations first. (Frangos, 2004)

A third type of mock-up process we will identify as Client-Driven/Standardization. In this type of mock-up, the design in question will be replicated many times and possibly 
across multiple projects, making it similar to the industrial examples mentioned before. As a result of the repeated use, mock-ups are used to identify any problems or concerns prior to mass production. A common user of this type of mock-up process is the hospitality industry. Marriott, for example, utilizes model rooms to fine-tune guest room design before implementing it throughout a hotel (or across an entire chain). (Swartz, 1985) Another way in which they use this type of mock-up is in creating a 'standard' prototype which establishes design criteria to which other designers must design in other projects that fall under the same brand. When Marriott recently revamped their Courtyard chain, they created not only model rooms, but also entire prototype hotels to test new lobby concepts before rolling them out chain wide. (Anon, 2004) Even companies such as McDonald's use this approach, hiring different firms to design new prototypes that are tested before becoming part of their catalogue of store designs from which a franchise can choose. One such example is Gensler, one of world's largest design services firms, which was hired to design prototypes in Colorado Springs, Colorado and Darien, Illinois. (Keegan, 1998)

Sometimes mock-ups are incorporated into the project after problems arise. These mockups we will refer to as Project-Driven. In these cases, mock-ups were not planned for in the initial stages of the project but were used in order to discover solutions when issues that arose during the normal design-build process. For the New York Times headquarters building designed by Renzo Piano, the Owner and the Architect of Record, FXFOWLE, decided on a competitive mock-up process for the structure's curtain-wall system. Building exteriors constitute a large percentage of a building's construction budget and 
the bids for fabricating the innovative curtain-wall design had all come in much higher than the Owner had desired. Much of this was based on a 'Fear Factor' associated with the contractors' lack of ability to base the construction of Piano's innovative design on previous work done. With no reference to help estimate the work, the numbers were inflated to help cover unanticipated costs. By choosing to then implement the competitive mock-up process, the Owner and Architect were able to give three competing curtain-wall manufacturers the same information from which to create a constructible solution that met the design criteria. When the contractors were able to work out the solutions prior to final bidding, all three came up with successful solutions and were able to produce final bids that were lower than earlier projections, saving the Owner millions. (Hart, 2008)

Finally, we look at one more type of mock-up process: the Designer-Driven/Research \& Development mock-up process. In this instance, the use of mock-ups was initiated by the designer for the purpose of testing and refining design ideas. To determine whether mock-ups have a role within the standard of practice for Interior Design, this is the most important use to study. It is being driven by the profession itself for the purpose of furthering design and creating new knowledge. If mock-ups are to become a common part of the services offered by the general profession, this use will likely show how it can be done. Bing Thom Architects, for example, have relied heavily on mock-ups to test elements of their designs that are innovative and new and they will often specify their use in contract negotiations. (Grdadolnik, 2004) As it is rare to find firms who use it as a 
standard, we will study a firm that does to ascertain why they do and to see if there are limitations preventing the greater profession from adopting this as a standard.

The mock-up process engages all parties in a construction project. By doing so, it tests not only methods of design and construction, but tests the process of collaboration as well. The parties must work together to implement a mock-up that is true to the design intent and meets the standards of construction being sought by the Owner. The parties must also come together after a mock-up is completed to examine it, identify issues present in it, and correct them prior to final construction of the project. The very process, beyond the realized mock-up itself, would seem to have value in honing the communication and collaboration of integrated practice teams. That said, though there appears to be potential benefit in mock-up use, we cannot say at this time why it isn't used more commonly. It is possible that a number of constraints - such as time and budget - factor in such a way as to deter their use. Mock-ups cost money and their coordination takes time. A project would need to be able to address these concerns to adopt mock-up use. As we have seen, however, at times the actual costs would have been significantly higher had mock-ups not been used.

It is important for Interior Designers to explore methods of practice that can yield improved collaboration and promote innovation in design. As demonstrated, there are many examples within the literature of the architectural and interior design professions that support the need for greater understanding within these concepts. In addition to testing collaboration, it could also be theorized that the use of a mock-up process can 
promote design innovation and serve as a knowledge generator by providing an outlet for testing new ideas. The use of a mock-up review process and its effect on the overall design process has not been greatly explored in the body of research of the profession. For these reasons, the research has direct value to the body of research knowledge for the profession, while providing insight directly applicable to the practice. 


\section{METHODS}

\section{Qualitative Approach}

A qualitative research strategy was selected as the method of investigation. Qualitative research is characterized by four key components (Groat \& Wang, 2002):

1. An emphasis on natural settings - the action or behavior being looked at happens in its normal, everyday setting

2. A focus on interpretation and meaning - the researcher seeks to interpret the collected data to look for meaning and significance

3. A focus on how the respondents make sense of their own circumstances the researcher attempts to paint a holistic portrait of the setting or phenomena as the subjects themselves understand it.

4. The use of multiple tactics - most, but not all, qualitative research employs multiple tactics to establish validity

Creswell (1994) provides six additional qualities of qualitative research:

1. It is holistic - encompassing, integrated

2. It involves prolonged contact - exposure to an actual field condition

3. It is open-ended - not limited to an objective or 'knowable' reality

4. The researcher is the device of measurement

5. It involves an analysis through words

6. It is characterized by a personal, informal writing stance 
Of the qualitative methods available, grounded theory was deemed the most appropriate for this proposal. As described by Groat and Wang (2002), grounded theory has many qualities that allowed it to provide a window into the data collected. Data collection, analysis, and the creation of theory are all closely related. Theories are derived from the data collected, not predetermined. Grounded theory is intensive, open-ended, and iterative - it is not a simple, closed experiment. Data collection, coding, and theory creation often occur simultaneously or in a back and forth fashion. Finally, grounded theory also assumes that the object of study cannot be fully understood on 'the first take' - it must be reexamined from multiple perspectives.

This proposed study was carried out using what Yin (2009) defines as a Replicated, Multiple-Case Design as its method of inquiry. The two cases chosen for analysis were the shipbuilding model, with its long-established history of mock-up use, and an experimental land-based studio that specializes in mock-ups as part of its process model. The study explored the overall philosophy regarding the use of mock-ups within the standard of practice, while also discussing specific examples in which the firms used mock-ups. By examining its use in such a way, the researcher would then frame its use within a firm to look at the greater context of the profession as a whole.

The multiple-case design called for the interview of a several professionals within the Interior Design industry, representing four unique perspectives from which to examine mock-up use. Within the shipbuilding model, interviews were conducted with two designers representing the cruise line. An interview was also conducted with the senior 
leadership of a design services firm that serves as one of the consulting interior designers working for the cruise line. Between these groups, mock-up use within shipbuilding could be discussed from both the owner/client and designer perspective, giving a more complete picture of the process. For the land-based case, interviews were conducted with senior studio leadership and with studio project management. This, again, allows for a greater analysis of this process. The motivating forces behind the establishment of the studio could be discussed with the firm leadership, while the practical use of the process could be discussed with project management. It is important to note that this part of the study focuses on mock-ups that are driven by the designer as part of a research and development model that is integrated as a standard component of their practice. This is significant because, as the literature has shown, there are several ways mock-ups are being used by the profession. It was important that how the selected firm used mock-ups be considered, with mock-up use being designer driven having the greatest potential relationship to how interior design as profession can utilize such a process.

This multiple-case design allows for the collection of a variety of viewpoints to the issue of mock-up use within design. The individual experiences of the involved professionals were examined for how the mock-up process was implemented and evaluated for the perceived effect its use had on the design outcomes. This will help identify whether the process has some universal benefit, or whether there are specific applications for which it may be better suited. 


\section{Data Collection}

The data was collected from a purposive sample. In a purposive sample, the researcher is concerned with discovering useful information patterns about a particular group or subset. (Groat \& Wang, 2002) In this case, that subset includes professional designers/design firms that have experience using a mock-up review process. Criteria for professional selection included, first and foremost, experience with a firm that has a history of mock-up use to the extent that it has become a standard of the firm's practice. This does not mean that every project will make use of mock-ups, but that their use by the firm has become common enough to have a standard procedure for its incorporation into a project, either across the firm's projects, within a studio of projects, or for a specific project type. Additional selection criteria included firm age, size, prominence, and innovation. Average size was determined by examining national averages provided by Interior Design and Architecture firms. (AIA, 2009) The selected firms were moderate to large-sized firm by AIA standards - in this study classified as a firm of 20 or more employees. While firms of this size represent only $10 \%$ of the total number of firms, they represent $62 \%$ of all employees, and $74 \%$ of all billings. (AIA, 2009) Thus firms of this size represent the majority of individuals trained in the design professions, and they also perform a majority of all work. Therefore, the firms were selected for their ability to represent the most professionals and the largest body of work. The shipbuilding-client model does not fit the traditional structure of a typical Architecture or Interior Design firm, but the criteria used to evaluate professionals was followed as closely as possible. 
Large firms represent a level of success and prominence within the profession. They have to maintain a large body of work in order to support their overhead. Prominence was determined by evaluating the firm's reputation. Reputation selection factors include project visibility and press coverage. These factors establish that the firm has been examined by experts in the field and determined to be both successful and prominent within the profession. Additional factors for professional selection were the age of the firm and average project size. A firm of longevity with large projects confirms client satisfaction and trust in the ability of the firm to enact a successful design process. These criteria were also used to determine firm innovation, as publication within professional periodicals is often tied to the use of new techniques or examples of new design trends.

Once a professional within the selected firm confirmed their willingness to participate and a briefing session was held, a formal interview was conducted that addressed the topics of study. The researcher examined the professional's experience, the motivations driving mock-up use, and what benefits or negative consequences they have found in doing so. The interview was open format, with the researcher guiding the discussion based on a set series of topics, while allowing the professional appropriate freedom to discuss the issues and those additional items they deemed relevant. This allowed for the discovery of issues that the researcher had not anticipated, allowing greater depth to the research.

Following the interview of the first professional, the researcher conducted interviews with other professionals fitting the different descriptions and criteria above, re-creating 
the open-dialogue format. Each session serves to help validate the others, while bringing to the surface a variety of issues and perspectives which could not be possible from interviewing one professional (or perspective) alone. Each interview throughout the process was documented by transcription. Any materials that were reviewed during the interview process were catalogued.

\section{Data Analysis}

The analysis uses a combination of manifest and latent content analysis via the use of coding. As Neundorf (2002) explains, this is analogous to looking for both 'surface' and 'deep' meanings within the interview contents. Manifest coding will look for obvious and countable traits that may surface, while latent coding will look for concepts that can be found via a series of indicators but that are not spelled out directly in and of themselves. In this way the content analysis will look for 'meaning' and the 'meaning behind the meaning'. Through coding, the major themes of each interview are identified by breaking out the coded sections and sorting them into categories.

Breaking apart the text into coded segments, however, is not enough. As Coffey and Atkinson (1996) explain, once broken apart the coded segments may lose their contextual value. Because interview data is often presented in narrative form, it is important to go back and look at the how the segmented themes interact within the narrative body of the interview. Here, the interview sections were analyzed to see how multiple codes were generated from the same section of text - suggesting a complex narrative with multiple 
themes. Theme clusters were determined by comparing how often one theme appeared alongside another. For example, in Interview \#2 Innovation appeared 13 times as a coded theme. In 6 of those instances, it appeared alongside Problem Solving, forming a cluster of Innovation/Problem Solving $46.2 \%$ of the time.

As the interviews occurred separately, each interview session was evaluated independently. Though each interview was looked at individually, they were examined using a common coding frame. The coding frame is the matrix of primary categories of interview subject matter, further explained in the next section. Once each interview was examined, the findings could be compared. The interviewing of multiple professionals reinforces the reliability of the findings by replicating the study across multiple subjects. This also strengthens the generalizability of the study and its findings to be applied to further cases in the future. (Yin, 2009) In other words, the multiple-professional approach helps prevent an overgeneralization of the findings, while also making the study more generally relatable to other cases in the future.

The peer review method has been used to ensure that the coding process is logical and appropriate and serves to validate the content analysis. In peer review, an outside consultant with the necessary skills and training to understand and evaluate the work, reexamines the coding of the primary researcher. Peer review validates that the researcher has applied the codes to the interviews appropriately and helps verify that the researcher has carefully applied the concepts of objectivity-intersubjectivity. (Creswell, 1998) In the case of this study, the peer reviewer was a design professional with at least a Masters 
level of education experience. The peer review and coding examination helps provide structural validity - "the degree to which an analytical construct models the network of stable relations in the chosen context." (Krippendorff, 1980) Finally, the results of the research were shared with the participating professional through the process of memberchecking (Groat \& Wang, 2002) for their review and reaction and to verify the analysis corresponds to their intended meanings. 


\section{RESULTS}

\section{The Coding Frame: Identifying the Major Themes}

The coding exercise yielded a variety of Major and Subordinate Themes. These themes centered around six major categories:

\section{Figure 1: Coding Frame}

\begin{tabular}{|l|l|}
\hline Major Theme Categories & Description \\
\hline Mock-up Process \& Methodology & Mock-Up \& Prototyping Process \\
\hline Innovation & New ways of doing things, exploration of design \\
& \& technique \\
\hline Design Process \& Methodology & Overall design process of which mock-up \\
\hline Collaboration \& Coordination & review is a part \\
\hline Costs / Cost Savings / Budgets & How people work together \\
\hline Professional Culture & Issues associated with project finances \\
\hline
\end{tabular}

Each of these categories and their related Subordinate Themes are elaborated upon below:

1. Mock-Up Process and Methodology explores the mock-up and prototyping process itself. Doing so separates it from the larger design process, which is 
explored in a later category. The reoccurring themes associated with this topic were:

A. Origins / Influences and Motivations for establishing the Process

B. Uses of the Mock-Up Review Process

1. Problem Solving

2. Quality / Refinement / Construction Validation

3. Aesthetics and Design Validation

C. Different Approaches / Project Typology

1. Client Driven

2. Designer Driven

3. Contractor Driven

4. Typology / Project Driven

D. 3D Physicality and Human Interaction

E. Areas for Improvement

1. Control and Use of Mock-Up Review Process

2. Innovation was initially coded under Uses in the previous category, but a further exploration of the issue indicated it merited its own category. This was partly due to innovation being described by the interview subjects as not only a part of the Mock-Up Process, but as a concept and ideology in its own right that transcended many of the categories listed. Therefore, here innovation now stands as new ways of doing things - an exploration of design and technique. Innovation is often explored through a research and development process where ideas are tested and refined. Above all, however, innovation evokes an idea of something that is cutting edge, without an established history. 
3. Design Process and Methodology explores the overall design process of which the Mock-Up Review Process is just one aspect. As related to the interviews it serves primarily to talk about the Architectural and Interior Design Process, as well as the Shipbuilding Process. The reoccurring themes associated with this topic were:

A. Comparing Methods

1. Land-based Projects versus Shipbuilding Projects

2. Architecture/Interior Design Projects versus Other Creative Professions (landscape, sculpture, etc)

a. Industrial Projects - Mass Production

3. American Projects versus European Projects

a. American Model $-1^{\text {st }}$ Dollar Driven / Low Bid

b. European Model - Lifecycle Driven / Maximum Guaranteed Price

B. Role of Mock-Up Review within Design Process

1. Mock-Ups versus other Pre-Build Techniques

a. Virtual Modeling

2. Impacts to Process Structure

3. Time / Schedule

C. Contracts / Contract Documents / Contractual Relationships / Liability

D. Codes \& Regulations - Influence on Process

4. Collaboration \& Coordination explores how the various parties involved in a design project work together and interact. This explores the actual working process as opposed to defining their contractual responsibilities, which is discussed above. This category essential divides itself into two areas:

A. Positive Collaboration / Team Environment 
B. Negative Collaboration / Adversarial Relationships

5. Costs / Cost Savings / Budgets explores the various issues associated with project financing including fees and construction budgets. The reoccurring themes associated with this topic were:
A. Marketing / Project Setup
B. Cost Savings (as benefit to using mock-ups)
C. Additional Costs (as deterrent to using mock-ups)
D. Project Budgets (Design \& Construction)

a. Value Engineering

6. Professional Culture explores the professional environment, including its history and perceived norms. It is divided into two areas:
A. Professional Culture - universal
B. Firm Culture - specific

These themes were reviewed for the number of times they appeared in each interview as well as for the their interactions with other themes. For example, knowing that Positive Collaboration was discussed more often than any other theme is an important piece of knowledge, but knowing that this topic was most often paired with Innovation further illuminates the significance of it.

The following chart presents a summary of the information presented above: 


\section{Figure 2: Code Chart}

\begin{tabular}{|c|c|c|c|c|c|}
\hline $\begin{array}{l}\text { Mock-Up Process \& } \\
\text { Methodology }\end{array}$ & Innovalion & $\begin{array}{l}\text { Design Process \& } \\
\text { Methodology }\end{array}$ & $\begin{array}{l}\text { Collaboration \& } \\
\text { Coordination }\end{array}$ & $\begin{array}{l}\text { Costs / Cost } \\
\text { Savings / Budgets }\end{array}$ & Prolessional Culture \\
\hline Origins \& Motivations & & $\begin{array}{l}\text { Land-based v. } \\
\text { Shipbuilding }\end{array}$ & Positive / TEAM & $\begin{array}{l}\text { Marketing / Project } \\
\text { Setup }\end{array}$ & Profession-wide \\
\hline Use: Problem Solving & & $\begin{array}{l}\text { Arch / ID v. other } \\
\text { Creative } \\
\text { Professions }\end{array}$ & $\begin{array}{l}\text { Negative / } \\
\text { Adversarial }\end{array}$ & $\begin{array}{l}\text { Cost Savings (as } \\
\text { benefit of mock- } \\
\text { ups) }\end{array}$ & Firm-Specific \\
\hline $\begin{array}{l}\text { Use: } \\
\text { Quality/Refinement }\end{array}$ & & Industrial Model & & $\begin{array}{l}\text { Additional Costs } \\
\text { (deterrent to using } \\
\text { mock-ups) }\end{array}$ & \\
\hline $\begin{array}{l}\text { Use: Aesthetic } \\
\text { Validation }\end{array}$ & & $\begin{array}{l}\text { American v. } \\
\text { European }\end{array}$ & & Project Budgets & \\
\hline Client-Driven & & $\begin{array}{l}\text { USA - 1st Dollar / } \\
\text { Low Bid }\end{array}$ & & Value Engineering & \\
\hline Designer-Driven & & $\begin{array}{l}\text { Europe-Lifecycle } \\
\text { Driven / MGP }\end{array}$ & & & \\
\hline Contractor-Driven & & $\begin{array}{l}\text { Mock-Ups v. other } \\
\text { Methods }\end{array}$ & & & \\
\hline $\begin{array}{l}\text { Typology / Project- } \\
\text { Driven }\end{array}$ & & Virtual Modeling & & & \\
\hline $\begin{array}{l}\text { 3D Physicality \& } \\
\text { Human Interaction }\end{array}$ & & Impacts to Process & & & \\
\hline \multirow[t]{3}{*}{$\begin{array}{l}\text { Areas for } \\
\text { Improvement/ } \\
\text { Control }\end{array}$} & & Time / Schedule & & & \\
\hline & & Contracts / Liability & & & \\
\hline & & $\begin{array}{l}\text { Codes \& } \\
\text { Regulations }\end{array}$ & & & \\
\hline
\end{tabular}




\section{The Interviews}

There were four interviews conducted, which included views provided by five different professionals who work with mock-ups as part of their normal work environment (two of the professionals were interviewed together). Each interview was scheduled for one hour and was semi-structured around a series of key topics and questions, though this structure allowed for the open discussion of issues which allowed the subject to introduce new topics of discussion. Based on the criteria presented in the Methodology section, these interviews will be categorized as follows:

1. Shipbuilding - Owner / Client

2. Shipbuilding - Design Senior Leadership

3. Land-based - Design Senior Leadership

4. Land-based - Design Management

The Coding for each interview is presented by examining the most commonly occurring themes. These themes are further explored by highlighting the themes to which they were most commonly clustered to search for relationships among the themes. For this research, the following criteria were established to demonstrate the strength of a clustered relationship: Any pair of themes that clustered more than $10 \%$ of the time is considered to have a demonstrable relationship. A theme clustered between $20 \%$ and $30 \%$ of the time is considered to have a significant relationship. Finally, a theme that was clustered more than $30 \%$ of the time is considered to have a very strong or substantial relationship with the primary theme being explored. It should be noted that any single references 
were disqualified, to reduce the risk of outliers, though some themes may have only appeared a handful of times.

Interview 1: Shipbuilding - Owner / Client

The Shipbuilding interview was conducted with two senior members of a major cruise line's design department. Both have backgrounds in design which include experience on land-based projects, but have decades of expertise specializing in cruise ships. This is an important fact to consider in reviewing their responses, as they have seen both areas of practice firsthand. Part of their role with the cruise line is the oversight of the various architecture and design firms that do design consulting work for the cruise line, some of which have a long history of working with the shipbuilding industry and some which are quite new to the process. This means that as part of this duty, these professionals must introduce the shipbuilding process to firms that have previously only done land-based work. This includes acclimating them to the use of mock-ups within their design process.

As might be expected, the topic brought up most often in the interview was the discussion of land-based design versus shipbuilding, as the interview delved quite heavily into the differences between the two types of work. The chart indicates those themes that surfaced $5 \%$ of the time or greater, followed by a breakdown of the theme clusters and the percentage of references to which each clustered theme appeared: 


\section{Figure 3: Interview 1: Identified Themes}

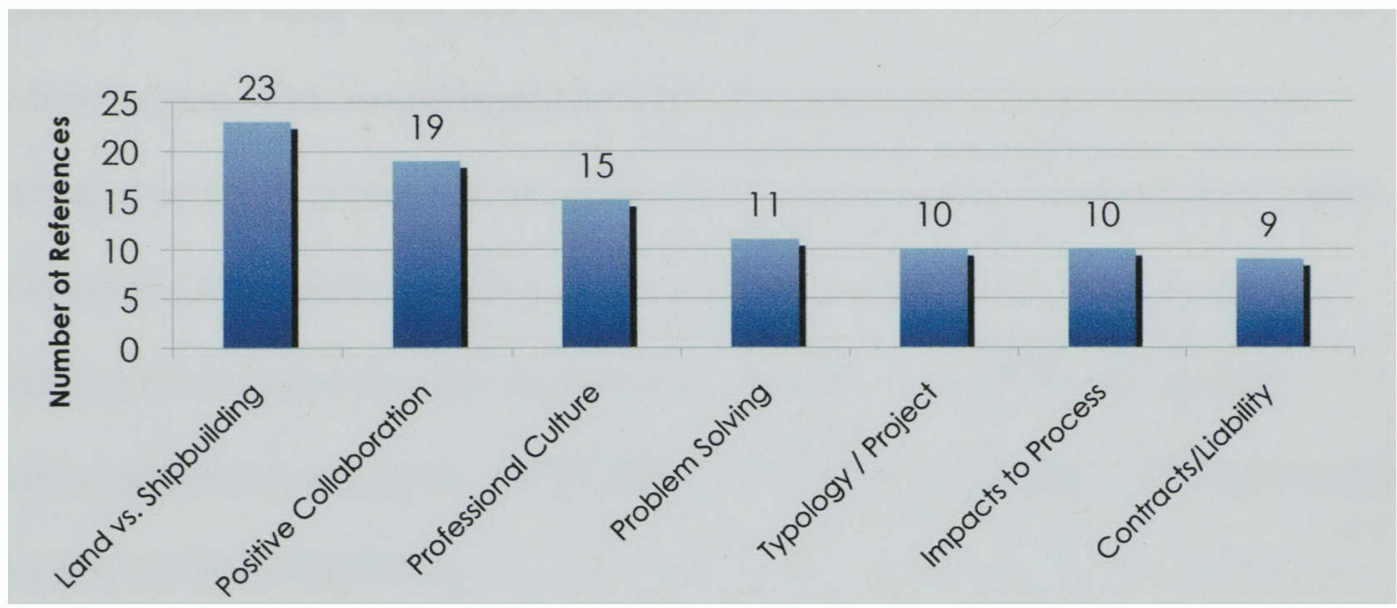

Figure 4: Interview 1: Thematic Clusters

Land-based Projects versus Shipbuilding (23)

- Positive Collaboration (43.5\%)

- Professional Culture (34.8\%)

- Liability / Contracts (26.1\%)

- Project Driven (21.7\%)

- Quality (13\%)

- Contractor (13\%)

- Time / Schedule (13\%)

- Codes \& Regulations (13\%)

-Additional Costs (13\%)

\section{Problem Solving (11)}

- Positive Collaboration (45.4\%)

- Innovation (36.4\%)

- Designer Driven (27.3\%)

- Aesthetics (27.3\%)

- Cost Savings (27.3\%)

- Contractor Driven (18.2\%)

- Land-based versus

Shipbuilding (18.2\%)
Positive Collaboration / Team Environment (19)

- Land-based versus

Shipbuilding (36\%)

- Problem Solving (26\%)

- Designer Driven (21.1\%)

- Contracts (21.1\%)

-Professional Culture (21.1\%)

- Quality (15.8\%)

-Impacts (15.8\%)

- Cost Savings (15.8\%)

- Contractor Driven (10.5\%)

- Innovation (10.5\%)

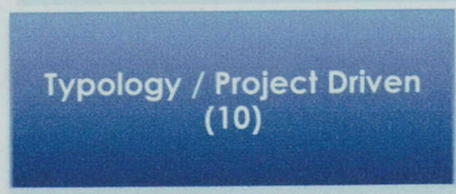

- Land-based versus

Shipbuilding (40\%)

- Designer Driven (20\%)

- Professional Culture (20\%)

\section{Professional Culfure (15)}

- Land-based versus

Shipbuilding (46.7\%)

- Origins (20\%)

- Negative Collaboration (20\%)

- Quality (13.3\%)

-Typology (13.3\%)

- Contracts (13.3\%)

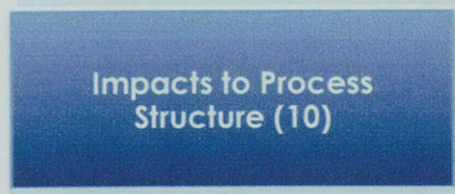

- Positive Collaboration (50\%)

- Land-based versus

Shipbuilding (20\%)

- Contracts (20\%)

- Firm Specific Culture (20\%) 
One of the most immediate issues that surfaces is the extent to which the discussion leans on the differences between land-based projects and shipbuilding. Not only does it appear more often than any other topic, but it also appears clustered with all of the other primary topics listed above. This would seem to support that there are important differences between the two kinds of projects, as explained in the introduction and expounded upon in the interview, that could affect how lessons from the mock-up review process in shipbuilding can be applied to land-based work. Having noted this, there are many indicators that this process serves a beneficial role to shipbuilding and, therefore, could to be beneficial to land-based work.

First, the Shipbuilding model as a whole seems to support positive collaboration, an idea that has become linked to the culture of shipbuilding itself. Collaboration is the most important aspect of the Integrated Practice model, as suggested by Pressman (2007), making this issue of paramount importance to the profession looking ahead. The mockup process is also directly related to positive collaboration and demonstrates such by being clustered a full $50 \%$ of the time when discussing the impacts mock-ups had on the overall process. Part of this support of positive collaboration may come from the differences in the contractual relationships of the parties involved. Designers hold significantly less liability in the shipbuilding industry, with the shipyard taking on the full brunt of the responsibilities of engineering and guaranteeing the performance and safety of the vessel. Designers do not sign and seal drawings as they do in the land-based work. As suggested by the professionals, it may be this key difference that actually drove the mock-up process within shipbuilding. The shipyard has a clear and vested interest in 
making sure every aspect of the ship functions and works - not only in terms of adherence to codes, but in terms of owner satisfaction. While the professionals interviewed could not say with certainty whether mock-ups originated from the client or the shipyard, there was strong support for the benefits they provided both parties. In fact, this mock-up review process has become firmly established within the shipbuilding model and serves as a standard of their process. As one of the professionals indicated, "It's just a part of the language. It's a part of the fabric of the project, the landscape of the process."

Collaboration statements were often clustered with problem solving statements within the interview. Problem solving is an important aspect of any complex design project. If we look at the clustered links found in the interview, we see that the mock-up process has a positive effect on collaboration within shipbuilding. We can then infer that, as collaboration is a key element required for problem solving, that mock-ups can serve as a vehicle for enhancing problem solving within a project. This would appear to be especially true in innovative projects, where the designer is pushing the envelope and exploring new techniques. Where a lack of precedent exists, the mock-ups serve to provide this test precedent for ensuring success of the final built environment. In other words, mock-ups act as a form of knowledge creation, which Robertson, Scarbrough, and Swan (2003) describe as being vital to a firm's success. This is supported by anecdotal evidence in the interview. One of the more interesting elements in the discussion related to the indoctrination of new design firms to the process and how the cruise line, as a client, observed how firms adapted to the process. The professionals interviewed spoke 
of at least two different firms that had begun developing their own mock-ups through the course of working on the ships. This was attributed to the success the firms found in working through the mock-up process with the shipyard, which then served to influence their own methods of problem solving.

The shipbuilding professionals also addressed the culture of shipbuilding versus the culture of land-based projects. The interview reiterated that the mock-up review had become part of the culture of how they work - they could not imagine the process without it. Within the discussion of land-based project culture, the topic of adversarial relationships between project stakeholders arose. Shipbuilding, in the eyes of its clients, is seen as a highly positive experience. It is seen as collaborative and dedicated to quality. Referring to the atmosphere of quality, one of the professionals indicated it came from the culture itself, "There's such a pride that comes out of those [referring to the shipbuilding contractors]." This aspect was also tied to the culture of Europe, where all the major cruise lines build their ships. It was suggested that the pride they observed as part of the shipbuilding process did not exist in land-based design, which was viewed as more competitive and cost driven. Additionally, land-based projects in the United States were viewed as trending away from an atmosphere of quality, while illustrating the failures Margerum (1999) associated with breakdowns in the collaborative process. While this discussion does not directly relate to the mock-up review process, it does seem to indicate that the atmosphere of design may prove to be a barrier for greater adoption of the process within land-based projects within the United States. 
Even within the shipbuilding industry, evidence suggests that mock-ups may best be served in specific projects or applications. While shipbuilding as a whole demonstrates unique needs to which mock-ups respond, within a ship wide project mock-ups are also employed based on priority. This is a process of negotiation the client has. with the designer and the shipyard. Here, priority is placed on spaces that are either highly repetitive or highly complex and innovative - spaces with design that is not "middle of the road' to quote one of the professionals. This, in turn, is associated with cost savings as the cost of correcting a mock-up prior to final construction is much less than the associated costs of altering or replacing elements within a final constructed environment.

A final key point can be made by examining not only which themes appeared most often, but looking at which appeared least often. In this case, the shipbuilding professionals were hard pressed to find areas to improve the mock-up process. It was viewed as being a strongly successful aspect of their overall process. Only upon reflection could they find examples of where the process could be improved, which related to having greater control of the process. Here it was suggested that the shipyard may have more information than the owner (especially in relation to costs) and could manipulate a mockup by showing something that might be able to be approved to save costs, while not fully disclosing that information to the owner. This fear itself was minimized and this example was explained as something that could happen, but not something they expected to happen. Again, this issue ties back to the client having an environment of trust and collaboration with the shipyard and its subcontractors. Ultimately, the one area they 
agreed upon for improving the process was looking for avenues of expanding it, not changing it.

Interview 2: Shipbuilding - Design Senior Leadership

This interview was conducted with a senior firm leader within a prominent architecture and design firm. Among the responsibilities of this individual is the running of the firm's cruise ship division, a specialty in which the professional has worked for two decades. In addition to cruise ship projects, this individual also oversees many land-based hospitality projects and participates with other firm leaders in the daily operation and strategic planning of the firm. This allows this individual to serve as a bridge between the landbased experience and shipbuilding. The unique insight offered can help identify why mock-ups, such a successful part of the shipbuilding process, have not become a standard of practice within the land-based profession.

Again, we see the topics cluster around the discussion of the differences between landbased projects and shipbuilding. The most common themes, and a breakdown of the theme clusters are as follows: 
Figure 5: Interview 2: Identified Themes

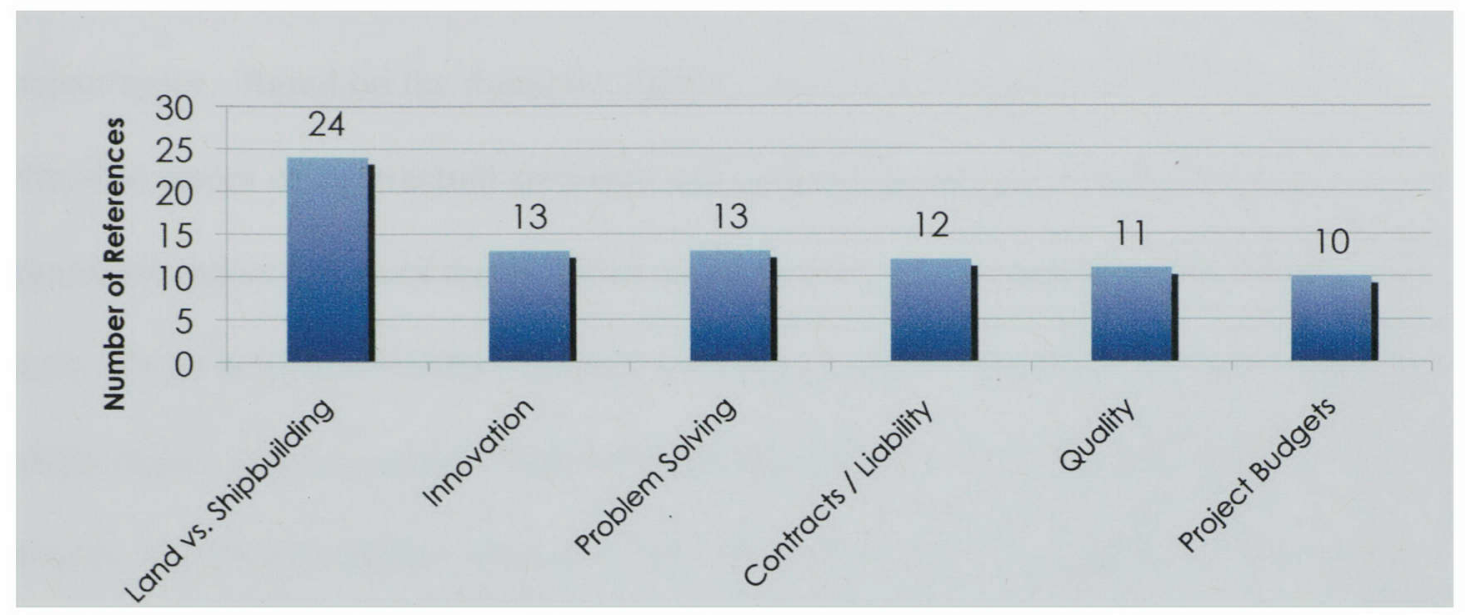

Figure 6: Interview 2: Thematic Clusters

\begin{tabular}{|c|c|c|}
\hline $\begin{array}{l}\text { Land-based Projects versus } \\
\text { Shipbuilding Projects }(24)\end{array}$ & Innovation (13) & Problem Solving (13) \\
\hline $\begin{array}{l}\text { - Quality (20.8\%) } \\
\text { - Contracts (20.8\%) } \\
\text { - Budgets (20.8\%) } \\
\text { - Problem Solving ( } 16.7 \%) \\
\text { - Positive Collaboration ( } 16.7 \%) \\
\text { - Innovation (12.5\%) } \\
\text { - American Projects versus } \\
\text { European Projects ( } 12.5 \%) \\
\text { - Negative Collaboration } \\
\text { (12.5\%) } \\
\text { - Professional Culture (12.5\%) }\end{array}$ & $\begin{array}{l}\text { - Problem Solving (46.2\%) } \\
\text { - Client Driven (30.8\%) } \\
\text { - Land-based versus } \\
\text { Shipbuilding ( } 23.1 \%) \\
\text { - Typology / Project Driven } \\
\text { ( } 15.4 \%) \\
\text { - Positive Collaboration ( } 15.4 \%)\end{array}$ & $\begin{array}{l}\text { - Innovation (46.2\%) } \\
\text { - Land-based versus } \\
\text { Shipbuilding (30.8\%) } \\
\text { - Positive Collaboration (23.1\%) } \\
\text { - Quality (15.4\%) } \\
\text { - Contracts (15.4\%) } \\
\text { - Cost Savings (15.4\%) }\end{array}$ \\
\hline Contracts / Liability (12) & Quality (11) & Project Budgets (10) \\
\hline $\begin{array}{l}\text { - Project Budgets (41.7\%) } \\
\text { - Land-based versus } \\
\text { Shipbuilding ( } 25 \%) \\
\text { - American Projects versus } \\
\text { European Projects (25\%) } \\
\text { - Negative Collaboration (25\%) } \\
\text { - Problem Solving ( } 16.7 \%) \\
\text { - Areas of Improvement ( } 16.7 \%) \\
\text { - Innovation (16.7\%) } \\
\text { - Professional Culture ( } 16.7 \%)\end{array}$ & $\begin{array}{l}\text { - Contractor Driven (36.4\%) } \\
\text { - Land-based Projects versus } \\
\text { Shipbuilding (27.3\%) }\end{array}$ & $\begin{array}{l}\text { - Land-based Projects versus } \\
\text { Shipbuilding (80\%) } \\
\text { - Contracts }(50 \%) \\
\text { - Negative Collaboration (40\%) } \\
\text { - Professional Culture }(30 \%) \\
\text { - Typology / Project Driven } \\
\text { (20\%) } \\
\text { - Innovation (20\%) } \\
\text { - American Projects versus } \\
\text { European Projects (20\%) } \\
\text { - Codes \& Regulations }(20 \%) \\
\text { - Positive Collaboration }(20 \%)\end{array}$ \\
\hline
\end{tabular}


As the individual interviewed currently oversees both land-based and shipbuilding projects it should come as no surprise that, by a large margin (nearly double the next most common theme), the discussion concentrated on the differences between the two project types. Based on the thematic clusters, we see that this discussion was strongly related to issues of contractual structure and project financing. This indicates that the organizational structure of the different projects types has an impact on how designers work. There were also evident clusters among the issues of quality, problem solving, collaboration, and innovation indicating that the project structure impacts not just the process, but also the design solution itself. Mock-ups were discussed as one of many aspects of the shipbuilding model that the professional deemed successful. The successes of the shipbuilding model centered largely on collaboration, which is heavily relied upon in making the mock-up process a success. It should be noted that references to positive collaboration centered on associations with the shipbuilding process, while references to negative collaboration centered on land-based work. This again may suggest that shipbuilding may be similar to the Integrated Practice model suggested by Pressman (2007) as being the future model of choice. While not centered on the discussion of mock-ups as a stand-alone entity, the discussion with this design professional indicates a strong preference for the process employed in the shipbuilding process. Citing a further relationship with professional culture, the environment of shipbuilding was compared to the environment of land-based projects, with the team approach of shipbuilding being brought into contrast with the more adversarial roles often associated in land-based work. 
The professional mentioned several times during the interview that the shipbuilding process was constantly pushing the envelope, "We're doing something that has not been done before." This support of innovation, both from a design and technical perspective, can be tied to the motivations and priorities of the owner/client. Innovation in shipbuilding becomes a process of taking the desires of the owner to push for something new and working together to solve the technical problems associated with the cuttingedge design elements. Mock-ups play a vital role in this process, a 'test' as referred to in the interview, and are a key method by which innovative designs are ultimately realized.

This method of employing mock-ups in problem solving and the clustered relationship with innovation suggests that where projects have a strong push (often by a motivated client) for new and untried design solutions, mock-ups may have a role in similarly innovative land-based design projects. It was noted that the initial motivation for the mock-up method might have originated with the shipyard, which holds contractual liability on the vessel. The mock-ups serve as a form of insurance that the design can be constructed to meet the dynamic conditions onboard a ship and that the owner will be satisfied with the solution. The method was also seen as resulting in a higher quality of product. These two factors can relate to cost savings, where costly repairs or redesign could occur if construction fails or the owner is not satisfied with the aesthetics of the design solution. Describing the process, the professional said, "It's a major design element in the space and we just want to make sure - I think the owner wants to make sure, the yard wants to make sure they can build it. They want to make sure the detailing looks good." 
As previously discussed, the shipbuilding model represents a host of contractual changes to the process that differentiates it from the land-based standard. Projects are financed differently and project budgets are quite different. Before most consultant designers begin the work of designing their respective spaces onboard a ship, the shipyard has already agreed to a construction price with the owner based on a reference vessel. With the cost of the ship already determined, ballooning construction costs are often contained and the designers work with the owner to bring their spaces into 'reference' - equal complexity - with their reference vessel and space. The discussion of these differences also prompted a discussion of the differences in building projects in Europe versus the United States. American project budgets are often being based on initial construction costs, while European budgets have a greater emphasis on lifecycle costs. European project budgets, similar to the shipbuilding process, are based on a maximum guaranteed price, rather than a low-bid process. This suggests that the culture of building in the United States may work against the adoption of mock-ups, as they are more likely to be seen in relation to their negative initial cost rather than a means to long-term cost savings.

On the topic of quality, the professional emphasized the importance of the contractor driving the process in the shipbuilding model. This, again, suggests a possible barrier to mock-up adoption in land-based work, or at least a conditional element to it. With emphasis on initial costs over lifecycle costs, quality can often be de-emphasized in the American model. This represents a failure of the stakeholders to form what Margerum (1999) called a Common Information Set of shared goals and objectives among all parties, with self interests being weighed above group interests. Without the commitment 
and push of the contractor driving quality concerns, the adoption of the mock-ups process in American land-based projects could prove difficult. The professional made several references to how the perception of quality in the shipbuilding process was markedly higher than the land-based projects on which the firm worked. This suggests that there are many issues and concerns with the American land-based project model that should be reviewed.

Interview 3: Land-based - Design Senior Leadership

The interview was conducted with a senior leader within a high-profile architecture and design firm. This individual is responsible for running an experimental studio within the firm that utilizes mock-ups and prototyping as part of its process. The projects are landbased projects, but are of no particular project type or size. Because of the uniqueness of this experiment and the relevance of it to the topic of study, much of the interview attempted to focus on the motivations for the formation of the studio within the firm. It is important to note that this individual comes from a background in industrial design, not architecture or interior design. One of the unique characteristics of the overall firm is its incorporation of creative talent from a multitude of professional backgrounds. This is an important perspective to keep in mind when reviewing the interview content.

The most themes most often cited in the interview and the clustered relationships were as follows: 
Figure 7: Interview 3: Identified Themes

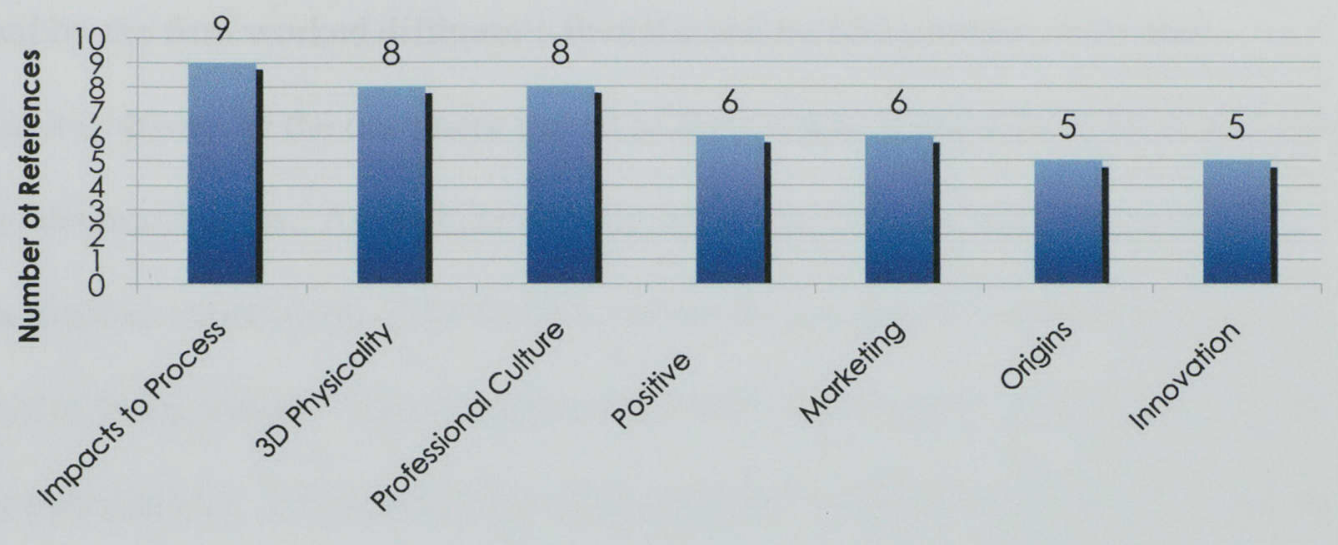

Figure 8: Interview 3: Thematic Clusters

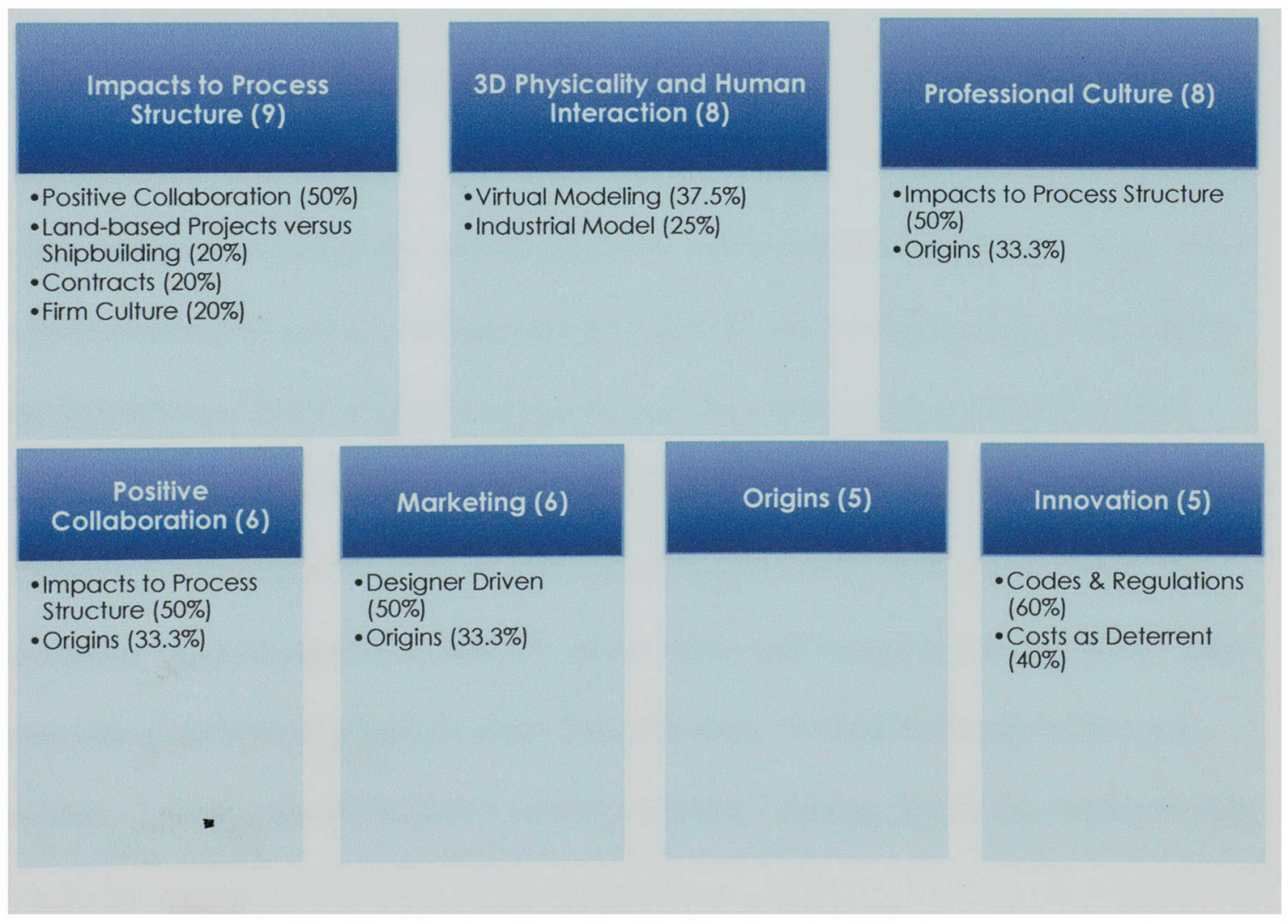


The most frequent reference in the interview was to how mock-up use affected the way in which the designers work. It was described as a highly collaborative process, but one that changed the very way in which designers approached their process. The process as employed by the firm worked differently than the shipbuilding model. First and foremost, it is driven by the designers as part of their research and development model of creating design solutions. As explained in the interview, "It grew out of the idea of having a place to experiment. [The firm] is known for using new materials and creating new ways of doing things." The designers themselves often build the mock-ups, instead of outside contractors. It is a part of the studio culture. They are not being driven by the contractor as a method of testing construction techniques or as an issue of controlling costs, though the studio often saw benefit from employing mock-ups for those reasons as well. The designers will often work with fabricators and contractors to refine construction techniques, but the driving force behind them is always the firm.

A key reason for adopting the mock-up process was the exploration of how things work in three dimensions and how human beings physically interact with design. Physicality was an important factor, representing something that could not be achieved by other techniques such as renderings or virtual modeling. The professional spoke of the dangers of relying too heavily on the virtual techniques, as they can be used to mask problems. Something can look right in a rendering which when built in reality does not work. This issue was given special emphasis when linked to scale, "I think that scale is always a problem. I always found that was a screen's mistake." Giving people the chance to walk 
around, touch, and generally interact with a design element often changes their perception of it.

The professional made several references to the culture of architectural work in the United States being a barrier to mock-up use. The largest area for improvement to the process was the idea of changing how architects and interior designers work. It was noted that architecture (from which interior design emerged as its own profession) is an old, established profession that has been slow to modify its historical process. Here the professional indicated the belief that architects tended to produce model of finished products, rather than utilizing mock-ups as a 'learning tool'. "It's hard to get them to change." The industrial model, which also employs many different kinds of designers, has almost uniformly adopted mock-ups as part of their normal process and seems more adept at adapting its model over time. This may suggest a reason for why the firm chose an industrial designer to head this studio experiment - that decision lends credence to the idea that a designer trained in architecture or interior design would have a difficult time adapting to the process and being able to maximize the benefits of it. It's simply a different method from which they are used to working.

The professional discussed how the mock-up process was a team effort that fostered greater collaboration throughout the design process. The positive impacts of it were one of the driving forces for adopting the model for the studio. It was noted that clients seemed to uniformly support mock-ups once presented with them. "Everybody loves mock-ups. It brings the thing to life." This suggests that a key to adopting mock-ups in 
land-based projects is greater exposure to the process by industry clients. This can play into a firm's marketing strategy. In the case of the subject firm, the use of mock-ups was accepted by its clients based, in part, on the firm's design reputation. The designers were able to sell their clients on the process because they had a reputation for trying new ideas. It was, therefore, not as surprising to clients to be asked to support a different way of working than that to which they might have been accustomed. Other times, the firm took the initial cost of the mock-ups upon themselves in order to help sell an idea or concept.

In regards to possible deterring factors, the effects of codes and costs were discussed. Upon the topic of how codes and regulations affect design, the professional dismissed the argument that they should negatively impact design or provide a barrier to mock-up use. They were seen as just another challenge that could actually help shape creative design in other words, the greater the challenge, the more creative the solution to it will be. While the costs of mock-ups could be seen as a deterrent, it was at that stage where the firm had to properly market them as a tool for innovation in order to achieve the client's desired results.

Interview 4: Land-based - Design Management

This interview was conducted with an individual project manager who worked within the studio overseen by the subject in Interview 3 . This is important because while the subject in the previous interview could address the discussion from the perspective of firm leadership, this individual can discuss it from the perspective of someone 'in the 
trenches' - it allows an opportunity to see if the perspectives of the leadership align with the perspectives of the people putting their experiment into practice. It is the intent of the interviews that the two different perspectives create a more complete picture of landbased mock-up use in mainstream, high profile interior design. As with the studio leadership, this individual comes from a background other than architecture and interior design - that of sculpture and fabrication. So, again, we see that the firm has made unconventional choices in its establishment and running of this studio. This would seem to enforce the idea that the process does work against the normal methods to which architects and designers have grown accustomed.

Within this interview, the themes and cluster relationships most often identified were:

Figure 9: Interview 4: Identified Themes

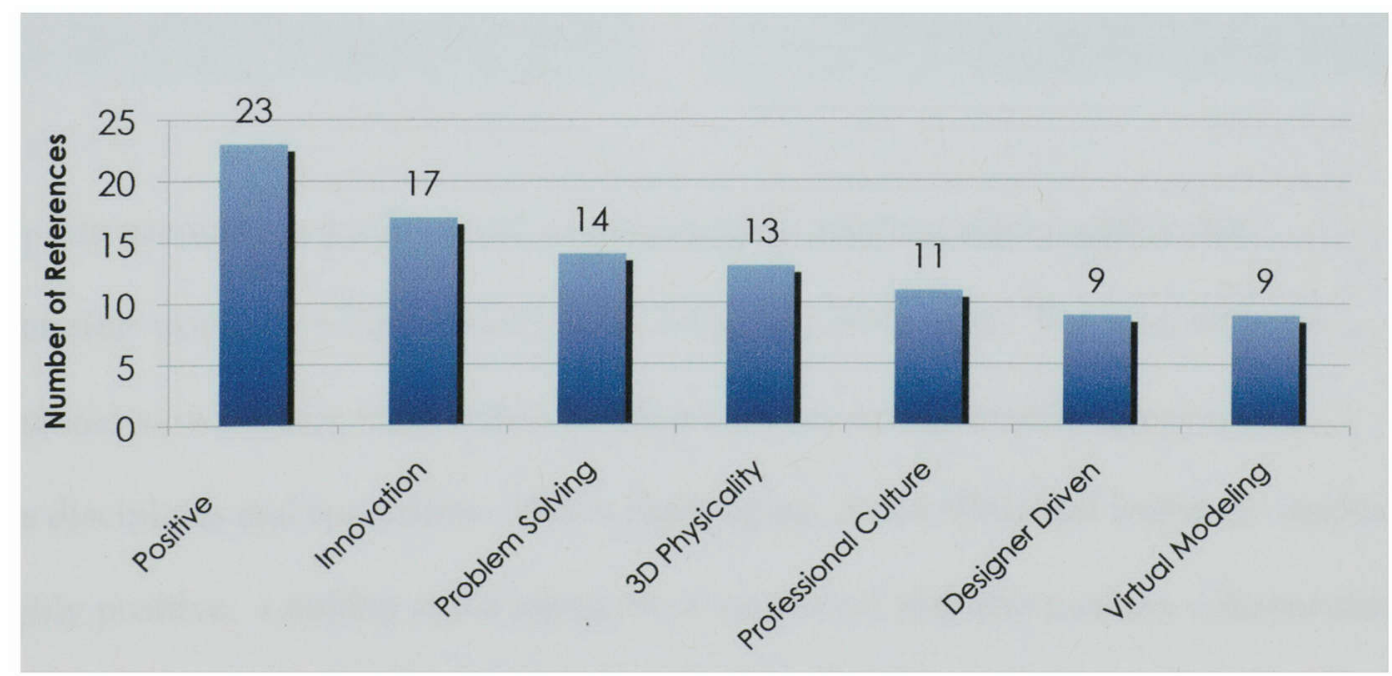




\section{Figure 10: Interview 4: Thematic Clusters}

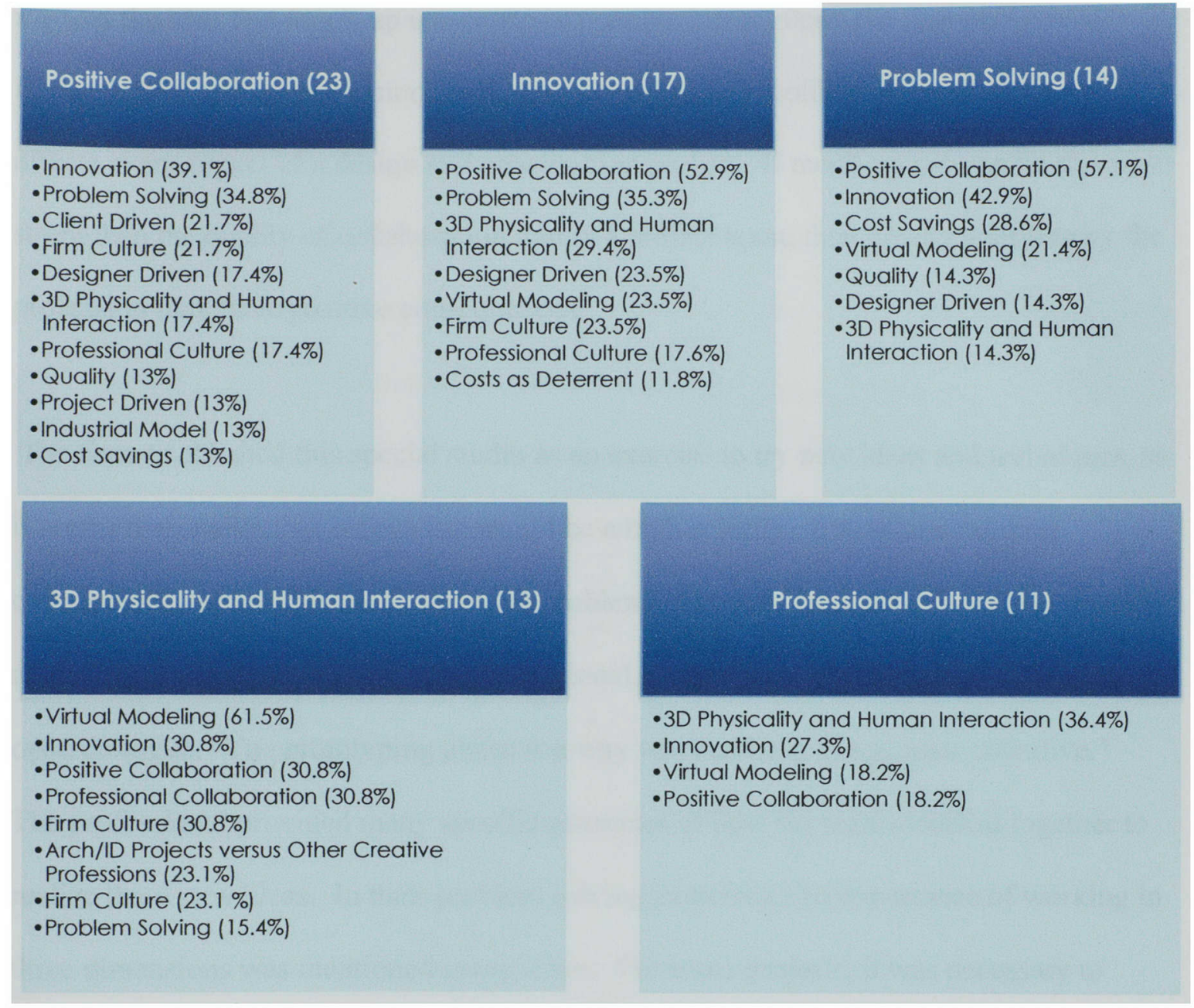

Taking into account the professional's background, it seems understandable that collaboration would be a high priority topic within the discussion. Working with the professional's own studio team within the firm requires a collaborative process that crosses disciplines and specialties. While challenging, the professional found the results are highly positive. Looking at the topics most associated with this positive collaboration - innovation and problem solving - we see a direct link to project design. Analysis uncovered strong clusters to client relationships and establishing a culture of 
collaboration that stretches beyond the studio and into the entire firm. These links support the idea that mock-up use creates a positive impact upon the process of design. It is also telling how many demonstrable links were made to collaboration - collaboration affects every aspect of a design and construction project. If mock-up use can be shown to strengthen the quality of collaboration within a project team, then greater adoption by the profession may have positive consequences.

The firm established this special studio as an exercise to try new ideas and techniques, so it seems reasonable that innovation would be a high priority. Innovation requires collaboration and teamwork to solve the problems that arise from doing something that's never been done. According to the professional, mock-ups aid in keeping a collaborative, open dialogue, "The prototyping phase is a way you can keep things open and alive." The professional provided many specific examples of how the teams worked together to realize these new ideas. In their problem solving exercises, the importance of working in three dimensions was mentioned many times. For some projects, it was necessary to explore the nature of the construction materials themselves, in others it was to explore issues of scale. Whatever the case, there was strong benefit seen to exploring these issues physically as opposed to virtually. This process was driven by the designers themselves and their desire to experiment - to 'play' as was the professional's description of the process. This was something which was positively associated with the firm's culture, but something which was identified as lacking in the professional culture of architecture and interior design as a whole. 
Problem solving went hand-in-hand with innovation - the more unique a design, the more unique the problems of the associated construction of it. Mock-ups enabled the designers to realize their concepts and refine them over time. Again, this was viewed as something that could not have been completely solved working in the virtual medium. The problem solving exercise was also viewed as having a positive impact by lowering costs. One specific example teamed the designers with software engineers for an installation - when the engineers created a breakthrough during mock-up testing, it lowered the labor costs for the rest of the project.

As the topic of the physicality and multi-dimensional nature of mock-ups was discussed so prominently, it also became clear this was something the professional felt passionate about. Part of this can likely be attributed to his background in sculpture and fabrication - in many ways, it was his preferred method of working for most of his career, unlike most architects and interior designers. The studio, however, was seen as having a positive impact on the firm and its methods were seen as benefitting the designs of the projects they were assigned. The professional used a comparison to drive an interesting point - if you drew the human body based not on size, but on the number of nerve endings, the drawing you produced would have enormous hands. The point the professional was trying to make was that human beings are wired to experience the world physically, through all of their senses and in three dimensions, saying, “...it's how we perceive space, lighting, color, texture, tactile..." From his perspective, it therefore makes sense that mock-ups can capture design in a way renderings cannot by nature of their ability to physically interact with people. If mock-ups are able to engage more of 
our human senses and perception abilities, then it would seem they could explore design in a way we cannot achieve using any virtual method. This could be of great benefit to interior design in particular. Interior design, more than related architecture, is about the areas of buildings that engage in physical human interaction. Any tool that allows designers to maximize their study of how a project's users will interact with the design should be explored within the profession for its usefulness.

There was discussion again made of the professional culture of architecture and interior design being a barrier to mock-up adoption. The professional brought up the importance of the professional culture being supportive of such efforts for them to succeed. Given the positive impacts witnessed within the firm, the professional felt architecture and interior design should be far more supportive of exploring physical mock-ups and prototypes - something embraced more readily by other professions. If mock-up use is to be widespread, it will have to be a cultural movement within the profession, but that movement will only gain momentum if pioneers continue to find success using the process. 


\section{Coming Together: Exploring the Interviews Collectively}

Examining each interview independently is important for ensuring that each interview is understood within its own context. Equally important is reviewing the interviews as a collective to see which topics and clusters emerged from group as a whole. This helps identify the issues of mock-up use that are of universal concern and importance.

The most common themes and clusters when taken collectively are:

Figure 11: Collective Identified Themes

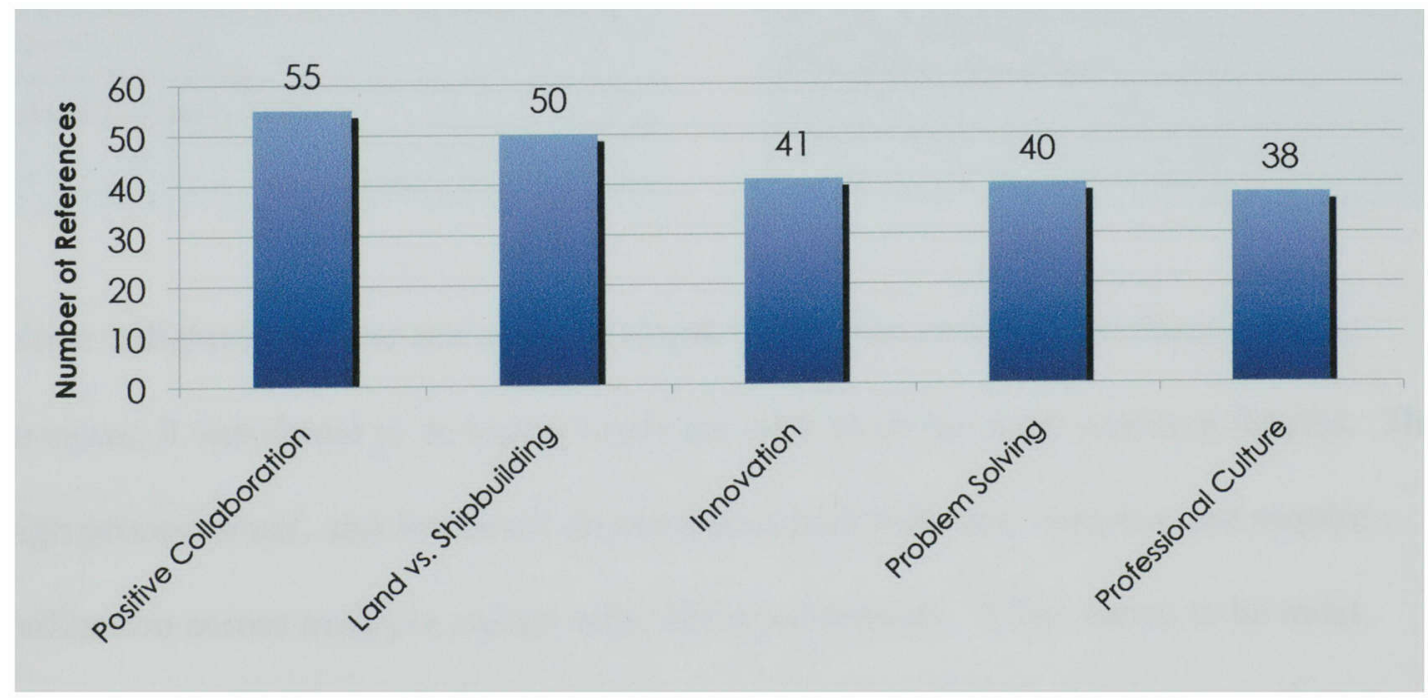




\section{Figure 12: Collective Thematic Clusters}

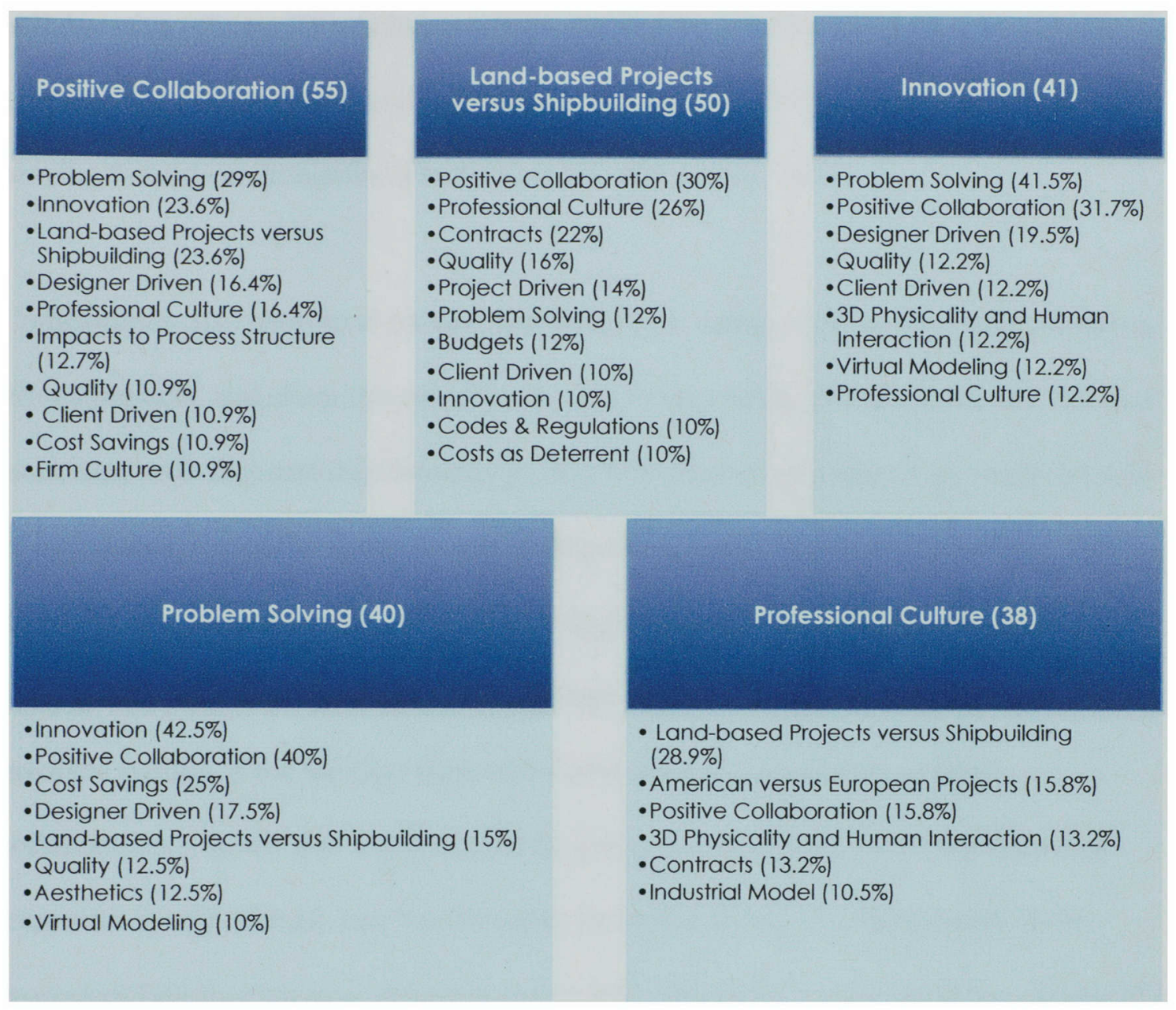

Positive collaboration was not only the single most referenced theme throughout the interviews, it was found to be highly clustered with all of the most common themes. The design process itself, and the mock-up process in particular, are complex and require coordination across multiple parties with different interests. What seems to be most relevant is that a discussion of using mock-ups yielded responses centered on positive collaboration. The views presented in the interviews represented designers and owners, firm leadership ('big picture') and firm managers ('practitioners' - 'doers'). Regardless 
of their perspective or position, they related the use of mock-ups to successful collaborative efforts. This is important in establishing whether mock-ups should hold a greater role in the overall practice of interior design, especially if the profession is truly moving towards an Integrated Practice model. (Pressman, 2007)

Collaboration also showed clustered relationships to cultural issues, use issues, designer driven projects, and client driven projects. The culture of shipbuilding was one that was associated with successful collaboration, but collaboration also played an important role in the culture of specific firms. It was an important aspect of the project whether being driven by the designer or the client. This suggests that different parties are capable of driving a successful project, but only with the coordinated teamwork of the other involved parties. Cost Savings were also found to be clustered with positive collaboration - again, this suggests that the goals of a project are best achieved when teamwork is emphasized, and benefits arise from that effort. If collaboration, in its process of bringing together different viewpoints, allows for a more complete picture of a situation to develop, it would seem to be understandable that cost savings would be found linked to that process. It allows for a better understanding of the issues at hand and allows greater opportunity for finding cost saving solutions.

With half the interviews conducted with professionals involved in the shipbuilding process, it was expected that the exploration of the differences in these processes would be a focal point of discussion. Indeed, the interviews were directed to explore these differences in order to see how mock-up use fits within the overall process and what 
issues would be present in trying to incorporate it into the land-based standard of practice. Again, the most prevalent clusters were in regards to collaboration and culture. Shipbuilding was viewed by its participants as having a collaborative nature. This suggests that the structure of the shipbuilding process might be examined further to look for possible lessons that could be applied to land-based projects in order to increase collaboration among team members. The interviews provide evidence that mock-ups are beneficial to collaboration, so the mock-up process may indeed be one such area that could be used to facilitate collaboration in land-based work. Mock-ups are an accepted part of the shipbuilding process that the participants had difficulty removing from the overall process - it has become an integral step that the team relies on. While this may make it more difficult to examine the specific relationship of mock-ups to the overall process, it does suggest validity to incorporating the process. Mock-ups had started at some point in the past, but they are a part of the process that has endured. This would suggest, beyond the interview opinions of support, that mock-ups are seen as beneficial to the design and construction of ships.

The strong connection with innovation may suggest that creative designs that are groundbreaking or employ new techniques may be better suited for mock-ups than standardized type designs. The interviews provide evidence through the clustering of the topic with problem solving that innovative projects may have more issues to resolve and that mock-ups are used as part of the problem solving methodology. This is significant because it suggests that innovation in a project is a quality that is valued and can be driven by either client or designer (or both). There has been an acceptance of an 
unconventional, or new, approach to the design solution by these parties. Thus, this analysis suggests that mock-ups provide these parties a collaborative means by which to test and refine their ideas. It serves as a vehicle for knowledge creation, which Lee and Kim (2001) have shown fosters competitive advantage. What is unclear from the interviews is whether mock-up use, in and of itself, can inspire innovation. It seems that the parties using mock-ups were inherently seeking innovative solutions as part of their design motivation. So, it could be that the mock-ups are a response to that motivation. It is also possible that their use encourages innovation, but the full range of ways in which mock-ups and innovation affect one another would need to be explored further.

Building upon the established relationship between innovation and problem solving, the interviews provide further reinforcement of the relationship between collaboration and problem solving. Solutions, it would appear, are best achieved through team effort or the Joint Decision Making process advocated by Margerum (1999). This method of working also seemed to be linked to examples of cost savings in the process. This would suggest further studies should examine how the initial costs of building mock-ups are weighed against their impact on long-term project costs. The interviews would seem to suggest that the potential for long-term savings outweigh the costs incurred in building the mockups. This is a limited study, however, and all the participants engage in high-profile, innovative design - whether this cost savings relationship would translate on a broader scale is unclear, but it does present a relationship which lends itself to further exploration. 
Finally, the discussion of mock-ups provided a forum for a discussion of professional culture - something that was not expected to be so prominent at the beginning of the research. Culture was discussed in many ways - shipbuilding versus land-based, European versus American, and architectural / interior design versus other kinds of professional models, particularly the industrial model. What the interviews suggest is a dissatisfaction by the professionals involved with the American land-based culture in building design and construction. When this was discussed as a general topic, almost all of the conversation turned to the negative impacts of it. It was viewed as having a detrimental effect on collaboration. The roots of this may lie in design pedagogy, where Joroff and Moore (1984) indicate the emphasis is on the individual over the group process. The contractual relationships seem to be perceived as strengthening adversarial roles, rather than collaborative ones. Interestingly, and most relevant to the incorporation of mock-ups, the project financing structure in American land-based work seems to serve as a deterrent being driven by a low-bid process where initial construction costs are prioritized over lifecycle costs. Discussions compared this directly to the idea that European projects are priced with operational and maintenance costs in mind and under a maximum guaranteed price of construction. The American system might therefore see mock-ups in terms of their cost to build, rather than in the savings they might provide in lifecycle costs. Those savings would be difficult to calculate without going through the process itself.

These concerns are viewed as uniquely associated with building construction - partly because buildings are a stand-alone entity. The industrial world embraces mock-up use, 
in part, because of the nature of mass production - if something fails, it will not fail once, but many times over. Because of this, the initial costs of doing a mock-up are seen in a different context. Shipbuilding, in this regard, falls closer to the industrial model, though it uses interior designers and architects to create the spaces onboard. The designs often appear on a class of ships, rather than on a single vessel (though this is not always the case, as the discussion of the Queen Mary 2 from the literature shows). The interviews did not address the issue in the light of repetitive construction techniques in land-based building projects - i.e. that though a design itself might not be repeated, the ideas learned might be re-used in later projects. This is a harder concept to evaluate as it spreads itself over time across many projects and teams, but it does suggest an untapped area for research exploration.

Finally, while not appearing as primary topics in their own right, the ideas of the physicality of mock-ups and their use versus other techniques surfaced in conjunction with many of the primary themes. This is important because the exploration of these issues opens the may help determine whether mock-ups are the best way of accomplishing the construction goals of a project. What emerged from the interviews was discussion of the benefits of the 3-Dimensional nature of mock-ups. Their very physicality was viewed as having a positive impact towards problem solving. To quote the land-based firm leadership from Interview 3, "You can fool yourself with a virtual mock-up." This suggests that virtual models are often thought of in regard to their aesthetic properties, not their problem solving aspects. By making something 'look good' in a virtual rendering designers (and clients) can be misled into assuming the 
design is resolved. Mock-ups force the design to be examined in a physical form that can be touched and experienced from multiple angles. Additionally, the points about human sensory exploration made by the land-based design manager in Interview 4 raise a host of questions about how human beings experience the environment around them. Virtual renderings rely on one sense - sight - as their sole means of exploring design. Interior design is 3-Dimensional and interactive with its human occupants. This study does not address the impact of relying solely on visual renderings to in design exploration, nor does it reveal the effects this has on the outcome or quality of the final environment. It does, however, raise many intriguing issues that suggest possible relationships and connections that further studies can build upon and explore. 


\section{CONCLUSION}

\section{Discussion}

At the heart of this research was the desire to understand the implications of incorporating mock-ups into the standard of practice. Based upon the analysis of the data provided, the following theoretical suppositions can be made:

1. Utilizing mock-ups facilitates collaboration. The research showed a strong relationship between the mock-up review process and collaboration. This collaborative exercise was viewed as beneficial, providing a medium for building and strengthening collaboration.

2. Utilizing mock-ups improves quality. The research indicated that the professionals viewed mock-ups as improving the final quality in both design and construction.

3. Utilizing mock-ups serves as a generator for knowledge creation and can foster creativity. The Innovation/Problem Solving cluster clearly showed an important relationship to mock-ups and creativity. Whether mock-ups promote creativity (a safety net for risk-taking?) or whether creativity seeks mock-ups as a result of formulating new, complex issues to resolve is unclear. What is clear is that the professionals interviewed saw mockups as part of the creative process, not as a barrier to it. Combined with the benefits seen to the collaborative process, mock-ups may provide a 
medium for allowing collaborative integrated practice teams to overcome Spiller's (2007) concerns.

4. Utilizing mock-ups has potential benefits to project structure and costs, but to see these benefits changes may be required to the standard practice model. It is clear that the subjects found mock-ups beneficial, but incorporating the process into the American practice model seems to be a source of difficulty. The study suggests that a re-examination of the entire project structure may be called for in moving design towards the new integrated practice model. This may reduce the barriers to wider mock-up use in practice, allowing potential lifecycle cost benefits to be valued.

\section{Limitations}

When exploring the lessons that can be pulled from the research, it is important to understand the context and limitations of the study and review the findings with these issues in mind. First, this study included a small number of participants and was conducted over a short period of time. The time constraints were a result of the research needing to be conducted in the fixed timeframe of the graduate program. The number of participants was a result of many factors. First, there are very few areas of the interior design profession where mock-ups are used as a standard of practice. Shipbuilding provides a unique avenue of study in this regard as it employs architects and interior designers and requires them to participate in a mock-up review process. Land-based usage of the process is far more limited. Interior Design, even when associated with 
architecture, is a small profession in terms of the number of people it employs. Looking for firms that utilize mock-ups as any standard form of practice requires looking for an extremely small group within an already small group. From this perspective, the study was fortunate to secure the participation of an established, reputable firm from which to conduct interviews.

Another limitation of the study is its reliance on interview data. Originally envisioned as a deeper case study, where the process of using mock-ups would be directly observed, the study was unable to accomplish this in the time allotted for the study. This, again, was the result of several factors, chief among them being the current impact of the economy on the interior design profession. In order for the process to be observed, it had to be ongoing during the time of the study. Interior Design, as a profession, has been extremely hard hit by the current economic downturn and the firms involved in the study all faced a significant loss of work during the time of the study. As a result, there were no projects currently utilizing the process that could be observed. Future research could work with a longer time frame to conduct the deep case study, following a project through its process and documenting the mock-up review process.

One area that can be seen as a limitation, while also providing insight of its own, is the lack of designers who participated in the land-based interviews. What is illuminating in this observation is that the design firm in question had purposely chosen the individuals who participated for their roles within the studio and the company. Clearly, the firm saw some advantage or benefit to having professionals with backgrounds outside of 
architecture and interior design running this experimental studio. Regardless of that background, the professionals in this studio worked on interior design projects and collaborated with designers as part of their process. Future research could revisit the firm to seek the participation of these designers and also investigate the impact of having their uniquely trained leadership. Conversely, it is interesting to note that all the participants from the shipbuilding side of the study came from backgrounds in architecture and interior design. Just as the land-based firm likely found benefit from having non-interior designers heading their studio, the cruise line clearly saw advantage to having designers in charge of their design department. This relationship could be more deeply explored in future research.

\section{Lessons from the Research}

While this limited research does not allow for the formulation of hard conclusions, there are a number of relationships that can be inferred from the analysis of the data. The theories put forth in the discussion are built upon these important lessons. First, utilizing a mock-up process appears to have a positive impact on collaboration. Of all the connections made, this is the most relevant to whether it can be viewed as successful. Secondly, mock-ups seem to be a strong tool for problem solving, particularly on innovative projects. This may suggest their greater use should focus on these types of projects, as opposed to becoming a standard for all project types. There seems to be support for the idea that mock-up use, while having associated initial costs, can have benefits that result in project savings in the long term. This is clearly an area for further 
research that goes into deeper study of these specific issues, but if found to be valid, provides a clear and positive motivation for greater mock-up use in interior design. It is also important to point out that all of the identified strengths of utilizing mock-ups are found as fundamental qualities of Pressman's (2007) Integrated Practice model.

The interviews also suggest that future research should focus on the professional culture of building construction in the United States. While not a focus of the study, the culture of land-based work fell under harsh criticism by all the participants in the study. This would seem to indicate that the current way the process is organized does not work to the full advantage and interests of its participants. More over, current land-based project culture in this country was linked to perpetuating adversarial relationships among its participants. This is an area of great concern for a profession that is moving ever more towards a collaborative model of Integrated Practice. It would also suggest a barrier to mock-up use within the land-based project environment. Addressing this may require new approaches to design pedagogy, where the root of professional culture is born. (Joroff \& Moore, 1984)

\section{Recommendations: Areas of Future Research}

There have been many examples given already where future research could expound upon or improve the research conducted in this study. Listed below are key recommendations for specific research opportunities, as suggested by the research analysis: 
1. Deep Case Study: Future research should take this study a step further by conducting direct observation of the mock-up process. This could then be further explored by studying how different firms or project types use the process in their work. The experiences of all involved parties - clients, designers, managers, and contractors - should be documented and analyzed.

2. Time and Number of Participants: Future research could be conducted without the time constraints that limited this study. This could have added benefit by allowing more time for finding and securing participants, but also increasing the ability of researchers to have access to ongoing projects in which they can observe mock-ups being used.

3. Related Research Opportunities: Future research can examine many of the issues that came to light as a result of this study. Professional Culture can be examined for its impacts on collaboration. Shipbuilding can be studied in greater detail to examine whether its entire project organization, not just its use of mock-ups, can provide lessons for improving land-based building projects. Contract and financing structures can be studied, including comparing those of other cultures, to see their impact on collaboration and perceived project success. 
These are but a few key areas that are readily suggested as open for exploration by this study. There are likely many more that other researchers can find in the data provided.

As a final thought, the research into mock-up use found success in several important areas. It proved an engaging topic to the research participants, who often had strong opinions of the process and the role it plays. It also served as a window into many related issues. It opened up a discussion of the overall process in building design and construction, while unearthing opinions about the nature of the profession and the impact of professional culture. These are important issues and represent the kinds of topics the profession needs to explore to guarantee its long-term success. Future research must expand upon the ideas presented and look deeper into the issues that arose. It holds this responsibility to the designers of the future, to help the profession grow and evolve to better serve its clients and users. Beyond this, there is a greater responsibility. Interior Design is a profession that impacts how every living person interacts with the physical world around them. The success of interior design directly affects how people live. Because of this, interior design as a profession must always seek out ways of improving its process and generating better results. For when interior design succeeds, it benefits everyone. 


\section{LIST OF REFERENCES}

Anon. (2004). Stylish new Louisville northeast Courtyard by Marriott first to showcase contemporary design package. PR Newswire, Year:2004 (Sept. 16), 1.

Anon. (2000). Voyager of the Seas: The largest ever cruise liner takes to the oceans. The Naval Architect, Year:2000 (2), 7-17.

Creswell, J. (1998) Qualitative inquiry and research design: Choosing amoing five tradiitons. Thousand Oaks, CA: Sage.

Creswell, J. (1994) Research design: Qualitative and quantitative approaches. Thousand Oaks, CA: Sage.

Coffey, A. \& Atkinson, P. (1996) Making sense of qualitative data. Thousand Oaks, CA: Sage.

Frangos, A. (2004, December 1). An office mock-up tests layout ideas. Wall Street Journal (Eastern Edition), p. B.1.

Garin, K. A. (2005). Devils on the deep blue sea: The dreams, schemes, and showdowns that built America's cruise ship empires. New York: Viking.

Groat, L. \& Wang, D. (2002). Architectural research methods. New York: John Wiley \& Sons.

Grdadolnik, H. (2004). Master builders [bing thom architects]. Canadian Architect, 49(9), 56-58.

Harmon-Vaughan, B. (2008). The case for collaboration. Implications, 4(3), 1-5.

Hart, S. (2008). Curtain-wall ingenuity eliminates the fear factor. Architectural Record, 196(2), 102.

Hunt, V. (2009). Royal Caribbean Cruise Lines, Celebrity Solstice. Hospitality Style, (January 2009), Retrieved May 31, 2009 from http://www.hospitalitystyle.com/content/royal-caribbean-cruise-lines-celebritysolstice

Joyce, L. (2003). Building a winner: Having a mock-up helps. $R \& D, 45(5) .31$.

Keegan, E. (1998). Happy meals. Architecture, 87(5), 100(4).

Krippendorff, K. (1980) Content analysis: An introduction to its methodology. Thousand Oaks, CA: Sage. 
Lee, J. \& Kim, Y. (2001) A stage model of organizational knowledge management: a latent content analysis. Expert Systems with Applications, 20 (2001) 299-311.

Lockledge, J. \& Mihailidis, D. \& Sidelko, J. \& Chelst, K. (2002). Prototype fleet optimization model. Journal of Operational Research Society, Year:2002 (53), 833-841.

Lubell, S. (2005). World Trade Center Memorial mock-up helps designers plan for the future. Architectural Record, 193(7), 32.

Margerum, R. D. (1999). Getting past yes: From capital creation to action. Journal of the American Planning Association, 65(2), 181-192.

Martin, C. \& Guerin, D. (2006) The interior design profession's body of knowledge (2005 ed.) University of Minnesota: Martin \& Guerin.

Neuendorf, K. (2002) The content analysis guidebook. Thousand Oaks, CA: Sage.

Newman, D. (n.d.) Royal Caribbean International review. Available from CruiseCritic.com website:

$\mathrm{http} / / / \mathrm{www}$.cruisecritic.com/reviews/cruiseline_page2.cfm?CruiseLineID=32

Paik, K. (2007) To infinity and beyond! The story of Pixar Animation Studios. San Francisco, CA: Chronicle Books.

Pressman, A. (2007). Integrated practice in perspective: A new model for the architectural profession. Architectural Record, 195(5), 116-118,120.

Pressman, A. (2009). It's a very good time to develop your firm's collaboration skills. Architectural Record, 197(4), 47-48.

Seguin, J. D. (2008). Data retrieval. Canadian Architect, 53(1), 35-36.

Spiller, N. (2007). Mythic collaboration. Architectural Design, 77(5), 130-131.

Swartz, S. (1985). Basic bedrooms: How Marriott changes hotel design to tap midpriced market. The Wall Street Journal, Year: 1985 (Sept. 18), 7-17.

Yin, R. (2009). Case study research: Design and methods. Thousand Oaks, CA: Sage. 
Appendix 1 - IRB Approval Letter 


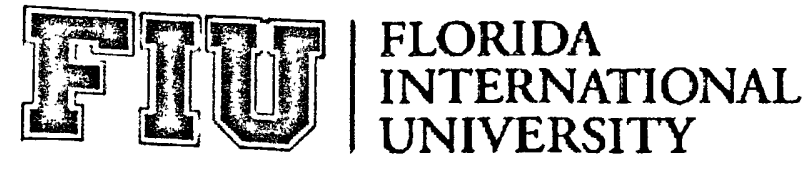

\section{MEMORANDUM}

To:

Charles Boggs

CC:

Dr. Janine King

File

From:

Jada Rauls, MPH, IRB Coordinator $q j$ K

Date: $3 / 4 / 10$

Proposal Title: "Mock-Ups in Design: The Implications of Utilizing a Mock-up Review Process in Professional Practice"

Approval \# 011510-02

Your study was deemed Exempt by the Institutional Review Board at Florida International University on Januray 15, 2010.

As a requirement of IRB approval you are required to:

1) Submit a completion report (Form B-2) upon completion of your project in order for the file to be closed.

2) Submit a proposal and receive approval for any additions or changes in the procedures involving human subjects.

3) Provide immediate written notification to the IRB of every serious or unusual or unanticipated adverse event as well as problems with the rights or welfare of the human subjects. You must confirm the receipt of serious AE reports with the IRB office.

Special Conditions: N/A

Please note your approval number is indicated above. For further information, you may visit the ORI - Human Subjects website at http://ori.fiu.edu/IRB.html. 
Appendix 2 - Interview Topics 


\section{Discussion Topics / Questions}

1. What were the motivating factors behind the adopting of a mock-up review process as part of your standard practice model?

2. Are there certain project types for which the firm promotes this process? Are there those for which they do not?

3. What are the benefits you've seen from using mock-ups?

4. How has using mock-ups influenced design at the firm? What affect has it had on innovation?

5. How has using mock-ups affected the process of collaboration? Are clients and contractors involved in the process? Consultants? To what extent?

6. How are the mock-ups financed? What are the costs to the firm of using mock-ups?

7. How does the mock-up process affect the final built project? Are changes to the design more or less likely?

8. How does a mock-up review influence construction quality?

9. How have clients responded to your use of this process? Do you have clients who are aware of your use of mock-ups prior to meeting with you?

10. What impact do you feel mock-ups have had on your quality of work? Your reputation?

11. How do you market using mock-ups?

12. How has the mock-up process affected your internal coordination? What affect does it have on deadlines and project schedules?

13. Has incorporating mock-ups into the process changed how your contracts are setup? How so?

14. Are there any flaws in the process as you see it? Are there problems that need to be resolved that would allow the process to be of greater benefit? 